\title{
Surfactant dysfunction and alveolar collapse are linked with fibrotic septal wall remodeling in the TGF- $\beta 1$-induced mouse model of pulmonary fibrosis
}

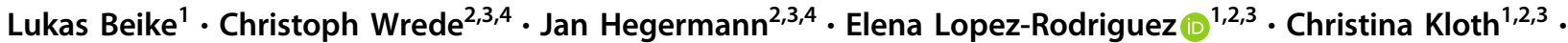 \\ Jack Gauldie ${ }^{5}$ Martin Kolb ${ }^{5}$ Ulrich A. Maus ${ }^{2,6} \cdot$ Matthias Ochs ${ }^{1,2,3,4} \cdot$ Lars Knudsen $\mathbb{1}^{1,2,3}$
}

Received: 6 July 2018 / Revised: 20 November 2018 / Accepted: 17 December 2018 / Published online: 30 January 2019

(c) United States \& Canadian Academy of Pathology 2019

\begin{abstract}
In human idiopathic pulmonary fibrosis (IPF), collapse of distal airspaces occurs in areas of the lung not (yet) remodeled. Mice lungs overexpressing transforming growth factor- $\beta 1$ (TGF- $\beta 1$ ) recapitulate this abnormality: surfactant dysfunction results in alveolar collapse preceding fibrosis and loss of alveolar epithelial type II (AE2) cells' apical membrane surface area. Here we examined whether surfactant dysfunction-related alveolar collapse due to TGF- $\beta 1$ overexpression is linked to septal wall remodeling and AE2 cell abnormalities. Three and 6 days after gene transfer of TGF- $\beta 1$, mice received either intratracheal surfactant (Surf-groups: Curosurf ${ }^{\oplus}, 100 \mathrm{mg} / \mathrm{kg}$ bodyweight) or $0.9 \% \mathrm{NaCl}$ (Saline-groups). On days 7 (D7) and 14 (D14), lung mechanics were assessed followed by design-based stereology at light and electron microscopic level to quantify structures. Compared with Saline, Surf showed significantly improved tissue elastance, increased numbers of open alveoli, as well as reduced alveolar size heterogeneity on D7. Deterioration in lung mechanics was highly correlated to the loss of open alveoli. On D14, lung mechanics, number of open alveoli, and alveolar size heterogeneity remained significantly improved in the Surf-group. Volumes of extracellular matrix and collagen fibrils in septal walls were significantly reduced, whereas the apical membrane surface area of AE2 cells was increased in Surf compared with Saline. In remodeled tissue with collapsed alveoli, three-dimensional reconstruction of AE2 cells based on scanning electron microscopy array tomography revealed that AE2 cells were trapped without contact to airspaces in the TGF- $\beta 1$ mouse model. Similar observations were made in human IPF. Based on correlation analyses, the number of open alveoli and of alveolar size heterogeneity were highly linked with the loss of apical membrane surface area of AE2 cells and deposition of collagen fibrils in septal walls on D14. In conclusion, surfactant replacement therapy stabilizes alveoli and prevents extracellular matrix deposition in septal walls in the TGF- $\beta 1$ model.
\end{abstract}

Supplementary information The online version of this article (https:// doi.org/10.1038/s41374-019-0189-x) contains supplementary material, which is available to authorized users.

Lars Knudsen

knudsen.lars@mh-hannover.de

1 Institute of Functional and Applied Anatomy, Hannover Medical School, Hannover, Germany

2 German Center for Lung Research (DZL), Partner Site BREATH (Biomedical Research in Endstage and Obstructive Lung Disease Hannover), Hannover, Germany

\section{Introduction}

Idiopathic pulmonary fibrosis (IPF) is a fatal, scarring lung disease with poor prognosis [1] and limited therapeutic options. High-resolution computed tomography (HRCT) usually shows volume loss and the formation of honeycomb cysts with a typical predominance in basal and subpleural areas of the lung resulting in an apico-basal gradient of

3 REBIRTH Cluster of Excellence, Hannover, Germany

4 Research Core Unit Electron Microscopy, Hannover Medical School, Hannover, Germany

5 Firestone Institute of Respiratory Health, McMaster University, Hamilton, Ontario, Canada

6 Department of Experimental Pneumology, Hannover Medical School, Hannover, Germany 
lesions [2]. With disease progression, these pathological alterations usually spread out from basal to more apical and from peripheral, subpleural to more central regions of the lung. Histological changes typically include a spatial and temporal heterogeneity meaning that different stages of the progressive pathogenesis co-exist in the same lung, a feature which is also present in end-stage IPF-lung explants [3]. Fibroblast foci and microscopic honeycombing can be found in close proximity to areas of the lung, which appear more or less normal $[4,5]$. It is in general accepted that IPF results from chronic injury of alveolar epithelial cells, impaired regeneration, and activation of invasive fibroblast responsible for excessive deposition of extracellular matrix (ECM) including collagen [6].

The role of increased transforming growth factor $\beta 1$ (TGF- $\beta 1$ ) signaling is well accepted in the context of pulmonary fibrosis [7]. TGF- $\beta 1$ is a pleiotropic growth factor and its effects on fibroblasts encompass activation, migration, and increased production of ECM components but also transdifferentiation to myofibroblasts. Hence, adenoviralmediated gene transfer of biologically active TGF- $\beta 1$ to the lung results in severe pulmonary fibrosis in rats and mice [8-11]. On the other hand, mice deficient in components of intracellular TGF- $\beta 1$ signaling such as Smad3 are protected against fibrotic remodeling $[12,13]$. Activation of TGF- $\beta 1$ requires its release from a large latent complex usually located in the ECM, where TGF- $\beta 1$ is bound to latencyassociated pro-peptide [14]. Mechanical stretch of lung tissue characterized by a remodeled and stiffened ECM has been shown to be a potential mechanism of TGF- $\beta 1$ release in animal models, but also in human IPF tissue, indicating that breathing can perpetuate pro-fibrotic signaling in a remodeled lung [15].

Adenoviral-mediated transfer of a porcine-derived active mutant of TGF- $\beta 1$ gene (AdTGF- $\beta 1$ ) by means of airway instillation results in a transient gene expression in the respiratory tract during the first week. Thereafter, the expression decreases [8] while the fibrotic remodeling continues $[8,11,16]$. A previous study showed that severe surfactant dysfunction and microatelectases represent the initial pathological findings during expression of active TGF- $\beta 1$ and occur in the absence of any fibrotic remodeling in the early phase [11]. Surfactant dysfunction could be attributed to TGF- $\beta 1$-induced downregulation of biophysically active surfactant proteins (SPs) B and C, and other components involved in surfactant biosynthesis in alveolar epithelial type II (AE2) cells [17], most likely due to lack of activity of thyroid transcription factor-1 in the nucleus [11]. In a second step, an increase in collagen fibrils in interalveolar septal walls was observed on day 14 of this model, whereas AE2 cells were subject to ultrastructural changes, characterized by a loss of surface area of the apical plasma membrane in relation to the baso-lateral plasma membrane
[11]. At electron microscopic level many AE2 cells were found within and between piled septal walls, completely surrounded by epithelial basal lamina. From these observations it was unclear whether these AE2 cells were still functional in terms of surfactant metabolism, as contact to airspaces was not visible. Taken together, direct effects on AE2 cells' function, which result in high surface tension at the alveolar air-liquid interface and alveolar collapsibility, are early events of TGF- $\beta 1$ gene transfer, a feature that is shared with other models of lung injury and fibrosis [18-20].

In human IPF there is also some evidence from imaging studies that collapse of distal airspaces occurs as an early event, meaning that instability of distal airspaces might predate the remodeling process. Using micro-computed tomography (and light microscopy for validation), microatelectases were observed in human IPF lung explants in the absence of fibrotic remodeling in areas that also appeared to be not (yet) remodeled according to HRCT imaging. Hence, alveolar collapse has been discussed as an important mechanism for the decline of lung function [21] and as a potential trigger of fibrotic remodeling [3], providing a possible structural mechanism for the transition from lung injury to fibrosis. Comparison of end-inspiratory and end-expiratory HRCT images from IPF patients revealed that abnormalities became obvious only under end-expiratory conditions in areas of the lung, which appeared unaffected at the end of inspiration [22]. These findings can be interpreted as resulting from endexpiratory loss of air due to collapsibility of distal airspaces in regions that are, according to HRCT findings, not yet remodeled. This also implicates that collapsibility predates the remodeling process [22]. In line with these observations are clinical findings that Velcro Crackles, supposedly resulting from explosive re-opening of distal airspace, predate the occurrence of chest X-ray abnormalities [23, 24]. In addition, severe surfactant dysfunctions are typical features of IPF patients [25]. Recent imaging studies provided evidence that the disease is active not only in areas of manifest fibrosis. Gadofosveset-enhanced magnetic resonance imaging suggests the existence of vascular leakage and therefore ongoing lung injury in areas of the IPF lung, which did not have visible fibrosis in HRCT [26].

Based on the observations mentioned above, it can be speculated that high surface tension-related alveolar collapsibility represents an independent trigger of injury and pro-fibrotic remodeling in the lung in the TGF- $\beta 1$ mouse model and also in human IPF. Hence, using the TGF- $\beta 1$ mouse model, two questions were addressed in this study: (1) Is surfactant replacement therapy efficient in stabilizing distal airspaces during the initial phase of the model, before the transition to fibrosis? (2) Is the stabilization of distal airspaces during the early phase linked to reduced profibrotic septal wall remodeling and AE2 abnormalities during the later phase, when the fibrosis has developed? 
Here we made use of the TGF- $\beta 1$ mouse model, in which effects on AE2 cells, surfactant function, and alveolar instability have been described recently [11]. As these described early effects of TGF- $\beta 1$ gene transfer seem to recapitulate observations in IPF lung explants characterized by microatelectases without further obvious signs of acute lung injury [3] in a realistic manner, it was considered that in the context of this study the use of the TGF- $\beta 1$ mouse model would be more appropriate than other models including the bleomycin model of acute lung injury and fibrosis. The latter also demonstrates microatelectases but these occur in the presence of typical features of acute lung injury such as influx of neutrophils, inflammation, swelling of epithelial cells, and vascular leak [18, 27, 28].

\section{Material and methods}

\section{Animals}

Fifty-six female mice (C57BL6/NCrl), aged 8 weeks, were purchased from Charles-River Laboratories (Sulzfeld, Germany) and housed in the animal facility of Hannover Medical School. All experiments were approved by the authorities of Lower Saxony, Germany (LAVES: Niedersächsisches Landesamt für Verbraucherschutz und Lebensmittelsicherheit), which houses the German equivalent of an institutional animal care and use committee, following the regulations of the European Animal Welfare Act (Approval No.: 16/2092).

\section{The animal model}

Animals were anesthetized in a Plexiglas chamber with $4.5 \%$ isoflurane in room air combined with subcutaneous injection of Butorphanol (Turbogesic ${ }^{\circledR}$ : $2 \mathrm{mg} / \mathrm{kg}$ bodyweight). Mice were orotracheally intubated using an Abbocath $16 \mathrm{G}$ Catheter. Dissolved in a volume of $50 \mu \mathrm{l}$ $0.9 \%$ saline, $10^{8}$ plaque-forming units of adenoviral vector (AdTGF- $\beta 1$ ) expressing biologically active TGF- $\beta 1$ were intratracheally instilled as described earlier $[8,9,11]$. The lungs were extracted 7 or 14 days after AdTGF- $\beta 1$ vector instillation. Ten animals served as healthy control group without vector instillation.

\section{Therapeutic interventions}

After adenoviral-mediated gene transfer, mice were randomized to the surfactant replacement therapy group (Surf group) or the Saline group for therapeutic interventions 3 and 6 days after gene transfer. The Surf group received intratracheal instillation of the porcine-derived surfactant preparation Curosurf ${ }^{\circledR}$, which was a gift from Chiesi Pharmaceutics (Parma, Italy) within the frame of an in kind donation. The dosage of Curosurf ${ }^{\circledR}$ per treatment was 100 $\mu \mathrm{g} / \mathrm{kg}$ bodyweight. Animals in the Saline group were treated intratracheally with an equivalent volume of $0.9 \%$ sodium chloride $(\mathrm{NaCl})$. The intubations were performed as outlined in the previous section. The control group did not receive any treatment.

\section{Lung mechanical assessment}

All animals were anesthetized via intraperitoneal (i.p.) injection of $80 \mathrm{mg} / \mathrm{kg}$ bodyweight ketamine (Anesketin, Albrech, Aulendorf, Germany) and $5 \mathrm{mg} / \mathrm{kg}$ xylazine (Rompun 2\%, Bayer, Leverkusen, Germany). After pain reflexes disappeared, a tracheotomy was performed and a 14-G cannula of $8 \mathrm{~mm}$ length was placed into the trachea. The cannula was then connected to the FlexiVent ventilator (SCIREC, Montreal, Quebec, Canada) followed by an additional i.p. injection of the same dosage of anesthesia as mentioned above, to verify a deep sedation of the animal during the lung mechanical measurements. Baseline ventilation parameters were as follows: tidal volume $10 \mathrm{ml} / \mathrm{kg}$, respiratory rate 150 breaths per minute, and an inspiration to expiration ratio of $1: 1.5$. The positive endexpiratory pressure (PEEP) was $3 \mathrm{cmH}_{2} \mathrm{O}$. After a 5-10 min run-in phase of stable ventilation, derecruitability tests were performed during $\mathrm{PEEP}=3 \mathrm{cmH}_{2} \mathrm{O}$ ventilation as described before [18]. The recruitment maneuver consisted of two deep inflations (= total lung capacity perturbations) to normalize volume history: during a ramp of $6 \mathrm{~s}$ the pressure increased to $30 \mathrm{cmH}_{2} \mathrm{O}$ and was kept stable for $3 \mathrm{~s}$. Next, the mice were ventilated with baseline settings for $5 \mathrm{~min}$ during which mechanical properties of the lungs were measured repetitively every $30 \mathrm{~s}$ by applying the forced oscillation technique. The resulting impedance spectra were fitted to the constant phase model to determine tissue elastance $(H)$, tissue dampening $(G)$, and Newtonian Resistance (Rn) [29]. For each individual the mean of ten tissue elastance measurements was calculated and reported in the results. Finally, quasi-static compliance $\left(C_{\mathrm{st}}\right)$ was calculated from pressure controlled pressure-volume loops [30]. The mean of three $C_{\mathrm{st}}$ measurements per individual is given in the results section. During lung mechanical measurements, the heart rate was monitored. In case of heart arrest before or during lung mechanical assessments, data were excluded, as lack of perfusion of the lung has a direct impact on lung mechanical parameters. Nevertheless, these lungs were immediately extracted for fixation and stereology or biochemical measurement of collagen content as outlined below. 


\section{Fixation and tissue processing}

After measurements of lung mechanics, animals were divided into two groups and processed either for designbased stereology or biochemical assessment of the hydroxyproline level. Lungs assigned to design-based stereology were subjected to a median sternotomy. The airway opening pressure was adjusted at $5 \mathrm{cmH}_{2} \mathrm{O}$ on expiration after a deep inflation and the trachea was ligated at a stable airway opening pressure of $5 \mathrm{cmH}_{2} \mathrm{O}$. Afterwards, the left atrium was incised and a cannula was placed in the right ventricle. Before the perfusion fixation with a solution of $1.5 \%$ glutaraldehyde, $1.5 \%$ paraformaldehyde, and $0.15 \mathrm{M}$ HEPES buffer at a constant perfusion pressure of $40 \mathrm{~cm} \mathrm{H}_{2} 0$ was started, the lung was flushed with $0.9 \% \mathrm{NaCl}$ until it became white. Lungs were dissected and stored in the fixative for at least $24 \mathrm{~h}$. Lung volumes were determined by means of fluid displacement based on buoyancy [31]. Lungs were then subjected to a systematic uniform random sampling for both light and electron microscopy as described previously [32]. Tissues sampled for light microscopy (5-8 pieces) were embedded in glycol methacrylate (Technovit 8100, Kulzer, Harnau, Germany) according to established protocols to minimize tissue deformation [33]. For light microscopic evaluation, embedded tissue was cut into sections with a thickness of $1.5 \mu \mathrm{m}$. Disector pairs were generated by collecting the firstand fourth section of a consecutive series of sections. For electron microscopic analysis, at least 6-10 tissue blocks were sampled per lung and embedded in epoxy resin (Epon) according to established methods [34]. Ultrathin sections of a thickness of approximately $60 \mathrm{~nm}$ were used for design-based stereology at electron microscopic level. Regarding the stereological parameters it was of utmost importance to avoid any leakage of air, e.g., as a complication of the dissection after fixation. Therefore, the lung volume as measured by fluid displacement was compared with the air displaced into the lung at the end of the fixation perturbation, corresponding to a stable end-expiratory airway opening pressure of $5 \mathrm{cmH}_{2} \mathrm{O}$. If the lung volume was below the volume of air displaced into the lung by the ventilator, the tissue had to be excluded from stereological analyses.

\section{Staining}

For light microscopy, sections were stained with $0.1 \%$ toluidine blue dye $(1 \mathrm{~g}$ toluidine blue diluted in $100 \mathrm{ml}$ of distilled water plus $2.5 \mathrm{~g}$ of sodium hydrogen carbonate), whereas samples for transmission electron microscopy were stained with uranyl acetate and lead citrate.

\section{Hydroxyproline}

Fourteen days after AdTGF- $\beta 1$ exposure, as well as in the healthy control group, the hydroxyproline content per lung was quantified. The pulmonary vessels were flushed with $0.9 \% \mathrm{NaCl}$. A smooth fractionator sampling design followed [35], resulting in a fraction of $1 / 4$ of the total lung in which lung hydroxyproline was measured. This sampling process allowed calculation of the total amount of hydroxyproline per lung by determining the total amount of hydroxyproline in the sampled tissue and multiplication with the inverse of the fraction [35]. A representative set of 7-10 tissue pieces per lung was sampled accordingly. The hydroxyproline measurement was based on a published methodology [36]. In brief, lung tissue was homogenized using a mechanical tissue lyser and dried at $65^{\circ} \mathrm{C}$ for $24 \mathrm{~h}$. Proteins were hydrolyzed using $37 \%$ hydrochloric acid $(\mathrm{HCl})$ at a temperature of $110^{\circ} \mathrm{C}$ for $24 \mathrm{~h}$. Finally, hydroxyproline was oxidized by means of chloramine $\mathrm{T}$ and color was developed with p-dimethylaminobenzaldehyde for photometric quantification. Multiplication of the hydroxyproline in the sampled tissue with the inverse of the fraction resulted in the total amount of hydroxyproline in the lung.

\section{Design-based stereology at light microscopic level}

Design-based stereology represents the current gold standard for quantitative assessment of three-dimensional (3D) structures by using two-dimensional sections and has been advocated as the method of choice by the European Respiratory Society/ American Thoracic Society recommendations on quantitative morphometry [37, 38]. Light and electron microscopical examinations were performed by a blinded observer. Applying the newCAST stereology software (Visiopharm, Horsholm, Denmark) equipped with the light-microscope DM6000B (Leica, Wetzlar, Germany) and a digital camera DP72 (Olympus, Hamburg, Germany), a systematic random area sampling was performed. An appropriate unbiased test system was superimposed on each field of view. Point and intersection counting were used to determine volumes and surfaces, respectively, whereas the physical disector was used to determine alveolar number. Stereological parameters including test system and primary magnification are defined in Tables 1 and 2. Determined parameters include those that were recommended in this disease area [39]. A cascade sampling design was followed [40].

In a first step the volume fraction of lung parenchyma $\left(V_{\mathrm{V}}\right.$ (par,lung)) was determined using a $\times 5$ primary magnification. Parenchyma was defined as fine lung structures 
Table 1 Stereological parameters measured at light microscopic level

\begin{tabular}{|c|c|c|}
\hline Parameter & Determination & Primary magnification \\
\hline Volume of parenchyma $V$ (par,lung) & Point counting & $\times 5$ \\
\hline Volume of septal wall $V$ (sep,lung) & Point counting & $\times 20$ \\
\hline Volume of ventilated alveoli $V$ (alvair,lung) & Point counting & $\times 20$ \\
\hline Volume of ductal airspace $V$ (ductair,lung) & Point counting & $\times 20$ \\
\hline $\begin{array}{l}\text { Total air-covered alveolar surface area } S \text { (alvair, } \\
\text { lung) }\end{array}$ & $\begin{array}{l}\text { Combined point/intersection } \\
\text { counting }\end{array}$ & $\times 20$ \\
\hline Arithmetic mean thickness of septal walls $\tau$ (sep) & $\begin{array}{l}=2 * V(\text { sep }, \text { sep }) / S(\text { alvair, } \\
\text { lung) }\end{array}$ & \\
\hline Total number of open alveoli $N$ (alv,lung) & Physical disector & $\times 20$ \\
\hline Number-weighted mean volume of alveoli $\nu_{\mathrm{N}}($ alv $)$ & $=V($ alv, lung $) / N($ alv,lung $)$ & \\
\hline Volume-weighted mean volume of alveoli $\nu_{\mathrm{V}}($ alv $)$ & Point sampled intercepts & $\times 20$ \\
\hline $\begin{array}{l}\text { Coefficient of variation of intraindividual alveolar } \\
\text { size distribution } \mathrm{CV}^{2}\left(\nu_{\mathrm{X}}(\mathrm{alv})\right)\end{array}$ & $=\nu_{\mathrm{V}}($ alv $) / \nu_{\mathrm{N}}($ alv $)-1$ & \\
\hline $\begin{array}{l}\text { Standard deviation of intraindividual alveolar size } \\
\text { distribution } \operatorname{SD}\left(\nu_{\mathrm{X}}(\mathrm{alv})\right)\end{array}$ & $=\mathrm{CV}\left(\nu_{\mathrm{X}}(\mathrm{alv})\right) * \nu_{\mathrm{N}}(\mathrm{alv})$ & \\
\hline
\end{tabular}

directly involved in gas exchange including alveolar and ductal airspaces, and septal walls $(\mathrm{sep}=$ parenchymatous tissue). Non-parenchyma consisted of conducting airways, blood vessels, or pleura, as well as associated perivascular and peribronchiolar connective tissue. Subsequently, the parenchyma was differentiated into alveolar airspace (alvair), ductal airspace (ductair), and alveolar septal walls (sep $=$ parenchymatous tissue) using a $\times 20$ magnification to determine corresponding volume fractions within lung parenchyma (par) such as $V_{\mathrm{V}}$ (alvair/par), $V_{\mathrm{V}}$ (ductair/par), and $V_{\mathrm{V}}(\mathrm{sep} / \mathrm{par})$. Alveolar and ductal airspaces taken together were defined as acinar airspaces ( $V_{\mathrm{V}}$ (acinair/par). The density of alveolar surface area covered with air was determined by a combined point/intersection counting and a primary magnification of $\times 20$. In general, at least 100-200 counting events per parameter and per lung were counted distributed on 5-8 sections and 100-200 fields of view generated during a systematic uniform area sampling process. This has been shown to result in a reasonable precision of stereological parameters [41].

Different volume fractions [e.g., $V_{\mathrm{V}}(\mathrm{sep}, \mathrm{par})$ : volume fraction of septal walls within parenchyma] were calculated by dividing counting events for the structure of interest [e.g., P(sep): points on septal walls] by all counting events in the reference space [e.g. $P($ par): points on parenchyma]:

$V_{\mathrm{v}}\left(\frac{\text { sep }}{\text { par }}\right)=\frac{\sum P(\text { sep })}{\sum P(\text { par })}$

The absolute volume of each component was calculated by multiplying its volume fraction with the volume of the reference space (e.g., total lung volume or total lung parenchyma):

$V_{\mathrm{V}}\left(\frac{\text { sep }}{\text { par }}\right) * V($ par, lung $)\left(\mathrm{cm}^{3}\right)=V($ sep, lung $)\left(\mathrm{cm}^{3}\right)$
Next, the surface area density $\left(S_{\mathrm{v}}\right)$ of air covered alveolar walls $\left(S_{\mathrm{V}}\right.$ (alvair,par)), representing the surface area within unit of reference space, was calculated by dividing the counted intersections (I(alvair)) of the test line with aircovered alveolar surface by the total length of the test line located in the reference space, which is the number of test line points on reference space ( $P($ line par)) multiplied with the length per point $(l / p)$ :

$S_{\mathrm{V}}\left(\frac{\text { alvair }}{\text { par }}\right)\left(\frac{\mathrm{cm}^{2}}{\mathrm{~cm}^{3}}\right)=\frac{2 * \sum I(\text { alvair }) * 10,000}{\sum P(\text { line par }) * l / p}$

Multiplication of $S_{\mathrm{v}}$ with the reference volume resulted in the surface area for the complete lung.

$S\left(\frac{\text { alvair }}{\text { lung }}\right)\left(\mathrm{cm}^{2}\right)=S_{\mathrm{V}}\left(\frac{\text { alvair }}{\text { par }}\right)\left(\frac{\mathrm{cm}^{2}}{\mathrm{~cm}^{3}}\right) * V($ par, lung $)\left(\mathrm{cm}^{3}\right)$

Finally, disector pairs were used to determine the density of open alveoli per volume parenchyma. The distance from the top of the first section to the top of the forth section resulted in a disector height of $4.5 \mu \mathrm{m}$. Using an unbiased counting frame with a certain area, a test volume was generated and within this test volume newly appearing alveolar openings were counted that was an alveolus, which was closed on the one section but open $(=$ connected to alveolar duct) on the other or the other way round [42]. The density of alveoli was multiplied with the reference volume to get the total number of open alveoli per lung ( $N(\mathrm{alv}$, lung)). The ratio of the total volume of the alveolar airspaces and the number of open alveoli resulted in the number-weighted mean volume of alveoli $\left(\nu_{\mathrm{N}}(\mathrm{alv})\right)$. In an additional step, point-sampled intercepts were used to determine the volume-weighted mean volume of alveoli $\left(\nu_{\mathrm{V}}\right.$ (alv)) [43]. The volume-weighted mean volume and the number-weighted mean volume are related to each other via 
Table 2 Stereological parameters measured at electron microscopic level

\begin{tabular}{|c|c|c|}
\hline Parameter & Determination & Primary magnification \\
\hline Volume of alveolar epithelial type 1 cells in septal walls $V$ (AE1,sep) & Point counting & $\times 11.000$ \\
\hline Volume of alveolar epithelial type 2 cells in septal walls $V$ (AE2,sep) & Point counting & $\times 11.000$ \\
\hline Volume of collagen fibrils within septal walls $V(\mathrm{col}, \mathrm{sep})$ & Point counting & $\times 11.000$ \\
\hline Volume of the residual extra- cellular matrix within septal walls $V(\mathrm{rECM}, \mathrm{sep})$ & Point counting & $\times 11.000$ \\
\hline Volume of interstitial cells within septal walls $V(\mathrm{IC}, \mathrm{sep})$ & Point counting & $\times 11.000$ \\
\hline Volume of capillary lumen within septal walls $V$ (caplumen,sep) & Point counting & $\times 11.000$ \\
\hline Volume of endothelial cells within septal walls $V($ endo,sep) & Point counting & $\times 11.000$ \\
\hline Surface area of capillary endothelia within septal walls $S$ (cap,sep) & Combined point-/ intersection counting & $\times 11.000$ \\
\hline Volume of lamellar bodies within the lung $V($ lb,lung $)$ & Point counting & $\times 8.900$ \\
\hline Surface area of apical membrane of AE2 cells $S$ (apicalAE2,lung) & Combined point-/ intersection counting & $\times 8.900$ \\
\hline Surface area of basolateral membrane of AE2 cells $S$ (blAE2,lung) & Combined point-/ intersection counting & $\times 8.900$ \\
\hline Apical/basal ratio & $S$ (apicalAE2,lung)/S(blAE2,lung) & \\
\hline
\end{tabular}

the coefficient of variation (CV) [44]. These data were used to calculate the intra-individual variability of alveolar size, in this case the SD of alveolar sizes within each individual $\left(\mathrm{SD}\left(\nu_{\mathrm{X}}(\mathrm{alv})\right)\right.$.

\section{Design-based stereology at electron microscopic level}

Electron microscopic examinations were performed by a blinded observer with a FEI Morgagni 268 transmission electron microscope (FEI, Eindhoven, Netherlands), a Veleta-Camera Side-Mount, $2 \times 2 \mathrm{~K}$ (Olympus Soft Imaging Solutions, Münster, Germany), iTEM-Software for image capturing (Olympus SIS, Münster, Germany), and the STEPanizer online tool [45]. For the image sampling, a systematic uniform area sampling was used [32] based on the XY-coordinate system of the stage to get an unbiased set of fields of view from six tissue blocks per lung. The systematic uniform area sampling resulted in 100-300 images of septal wall tissue which was now, following the cascade sampling strategy, the reference space for quantification of the composition of septal walls/ parenchymatous tissue. Point counting and intersection counting were used for the measurements. In the first step, the volume of alveolar type I (AE1) and type II (AE2) epithelial cells, collagen fibrils (defined by ultrastructural criteria), interstitial cells, capillary lumen, and ECM other than collagen fibrils such as basal lamina or elastic fibers was determined by point counting. The surface area of the capillary endothelium was determined by intersection counting. In the next step of the cascade sampling design, the total volume of AE2 cells in the septum represented the reference space. Images of all AE2 cells per section were captured on the six slices and the volume of the lamellar bodies and the surface of the apical and basolateral (including tight junctions) membranes of AE2 cells were determined by point and intersection counting, respectively.

\section{Scanning electron microscopy array tomography and $3 D$ reconstruction $A E 2$ cells}

The samples were stained en bloc by using the rOTO protocol (rOTO: reduced osmium tetroxidethiocarbohydrazide-osmium tetroxide) to get enough contrast of the biological structures and a good conductivity of the sample in the scanning electron microscopy (SEM). Tissue was embedded in Durcupan ${ }^{\mathrm{TM}}$ ACM resin (SigmaAldrich, St. Louis, USA). The protocol used is based on Deerinck et al. [46], here in brief including adaptions: fixation in 0.15 M HEPES buffer with $1.5 \%$ glutaraldehyde and $1.5 \%$ paraformaldehyde, $\mathrm{pH} 7.35$ for about $2 \mathrm{~h}$ at room temperature and overnight at $4{ }^{\circ} \mathrm{C}$; the samples were washed $2 \times 5$ min with HEPES buffer $(0.15 \mathrm{M}, \mathrm{pH} 7.35)$ and $4 \times 5$ min with cacodylate buffer $(0.1 \mathrm{M}, \mathrm{pH} 7.35)$; incubated in $1 \%$ reduced osmium tetroxide $(0.1 \mathrm{M}$ cacodylate buffer $\mathrm{pH} 7.35$ with $1.5 \%$ potassium hexacyanoferrate(II) trihydrate) $30 \mathrm{~min}$ in the dark; rinsed $3 \times 5 \mathrm{~min}$ with $\mathrm{ddH}_{2} \mathrm{O}$, followed by $20 \mathrm{~min}$ thiocarbohydrazide solution (TCH, 1\% in $\mathrm{ddH}_{2} \mathrm{O}$ ); rinsed again $3 \times 5$ min with $\mathrm{ddH}_{2} \mathrm{O}$ and incubated in $1 \%$ osmium tetroxide in $\mathrm{ddH}_{2} \mathrm{O}$ for $30 \mathrm{~min}$ in the dark, rinsed $5 \times 5$ min with $\mathrm{ddH}_{2} \mathrm{O}$ and incubated overnight in half-saturated water-uranyl acetate solution (freshly prepared from $8 \%$ stock solution) at $4{ }^{\circ} \mathrm{C}$ in the dark; after washing $3 \times 5$ min with $\mathrm{ddH}_{2} \mathrm{O}$ samples were stained en bloc with Walton's lead aspartate for $30 \mathrm{~min}$ at $60^{\circ} \mathrm{C}$ and washed again $3 \times 5 \mathrm{~min}$ with $\mathrm{ddH}_{2} \mathrm{O}$, followed by a dehydration series: $70 \%, 80 \%, 90 \%$ acetone (each step $2 \times 5 \mathrm{~min}$ ), $3 \times 100 \%$ dried acetone (each $10 \mathrm{~min}$ ); samples were infiltrated in Durcupan resin $(25 \%, 50 \%, 75 \%$ 


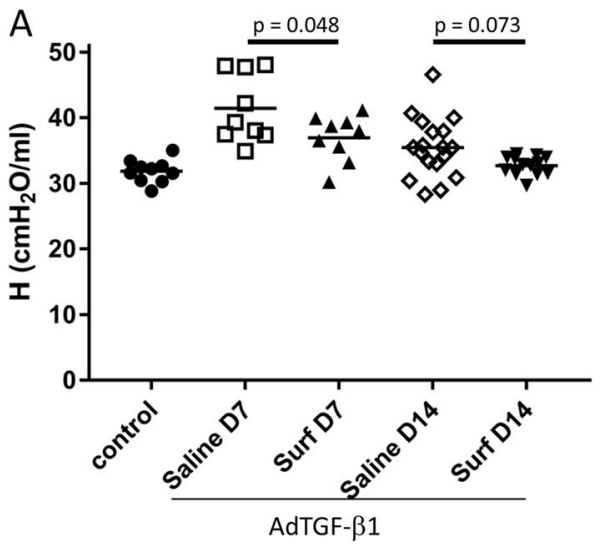

Fig. 1 Lung mechanics. Tissue elastance (a) and quasi-static compliance (b) were used to characterize the lung mechanical properties in the study groups on day 7 (D7) and day 14 (D14). Surf groups were treated with intratracheal surfactant (poractant alpha) on days 3 and 6

Durcupan in dried acetone for $2 \mathrm{~h}$ each, $1 \times$ washed in $100 \%$ resin, then $100 \%$ resin overnight and fresh resin for $2 \mathrm{~h}$ on the next day) and were polymerized at $40{ }^{\circ} \mathrm{C}$ overnight, followed by $48 \mathrm{~h}$ at $80^{\circ} \mathrm{C}$.

For 3D analysis of the mouse lung samples by array tomography, $300 \mathrm{~nm}$ sections were cut and serial section ribbons of about 25 sections were collected on glass microscope slides (microscope slides were incubated $24 \mathrm{~h}$ in $\mathrm{ddH}_{2} \mathrm{O}$ before use), and incubated on $60-65^{\circ} \mathrm{C} \mathrm{ddH}_{2} \mathrm{O}$ to remove wrinkles. Sections were dried on a warm plate at $45^{\circ} \mathrm{C}$ and finally fixed at $80^{\circ} \mathrm{C}$ for $30 \mathrm{~min}$. About 665 sections on 26 microscopy slides were analyzed by light microscopy using phase contrast. For array tomography, the microscope slides with the identified region of interest (ROI) were mounted for SEM analysis on SEM stubs (12.7 $\mathrm{mm}$ diameter) with conductive carbon tape, treated with conductive silver (encircling the sections), and coated with a thin carbon layer. The ROI was imaged with the Zeiss ATLAS System combined with a Zeiss Crossbeam 540 (Carl Zeiss Microscopy GmbH, Jena, Germany). ROI on 75 sections were recorded with the BSD4 detector at $3.5 \mathrm{kV}$ acceleration voltage and $0.5-2 \mathrm{nA}$ current with a pixel size of $5 \mathrm{~nm}$. Fiji software was used for image processing (https://fiji.sc/). Segmentation was performed with Microscopy Image Browser (http://mib.helsinki.fi) and visualized with 3D Slicer (http://slicer.org).

\section{Statistical analyses}

The hypotheses were that surfactant replacement therapy keeps alveoli open at D7 and reduces pro-fibrotic remodeling at D14. Therefore, a one-way analysis of variance followed by Sidak's adjustment of the $p$-value was performed at D7 and D14 separately. Correlation analyses were performed using a Spearman's test. Statistically significant

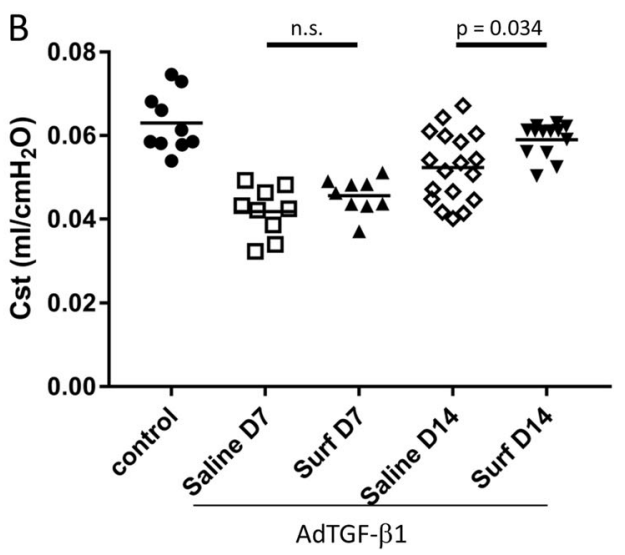

after adenoviral-mediated gene transfer of active TGF- $\beta 1$ (AdTGF- $\beta 1$ ), whereas saline groups received $0.9 \%$ sodium chloride solution. The control group demonstrates healthy conditions for comparison. n.s.: not significant

differences were accepted for $p<0.05$, whereas a nonsignificant trend was described with $p<0.1$. Adjusted $p$-values are provided only for $p<0.1$ between Surf and Saline at the corresponding time point D7 or D14. Statistical tests were performed using SPSS statistic software package Version 25.0 (IBM Corp., Armonk, NY). For graphical illustration of data Prism Graphpad version $7.0(\mathrm{GraphPad}$ Software, La Jolla, CA, USA) was used.

\section{Results}

\section{Lung mechanical data}

Figure 1 illustrates individual data as well as groups' mean of tissue elastance $H$ and quasi-static compliance Cst of healthy controls and Saline vs. Surf on D7, as well as on D14. Tissue elastance demonstrated a slight but statistically significant decrease on D7 in Surf compared with Saline (Fig. 1a), whereas on D14 there was at best a trend $(p=0.073)$ in favor of the Surf group. The findings regarding Cst did not show any effects of surfactant replacement therapy on D7, whereas on D14 a significant increase was detected in the Surf group compared with the Saline group (Fig. 1b). Of note, on D14 there was a remarkable variability in the Saline group regarding $H$ and Cst with some data in the range of values, which can be found under healthy conditions. In the Saline group on D14, however, quite a large proportion of measurements was clearly worse than the level found in healthy controls. This was not the case in the corresponding Surf group. In other words, the distributions of $H$ and Cst in the Surf group were on D14 more similar to the control group than the distributions of the data points in the Saline group. 

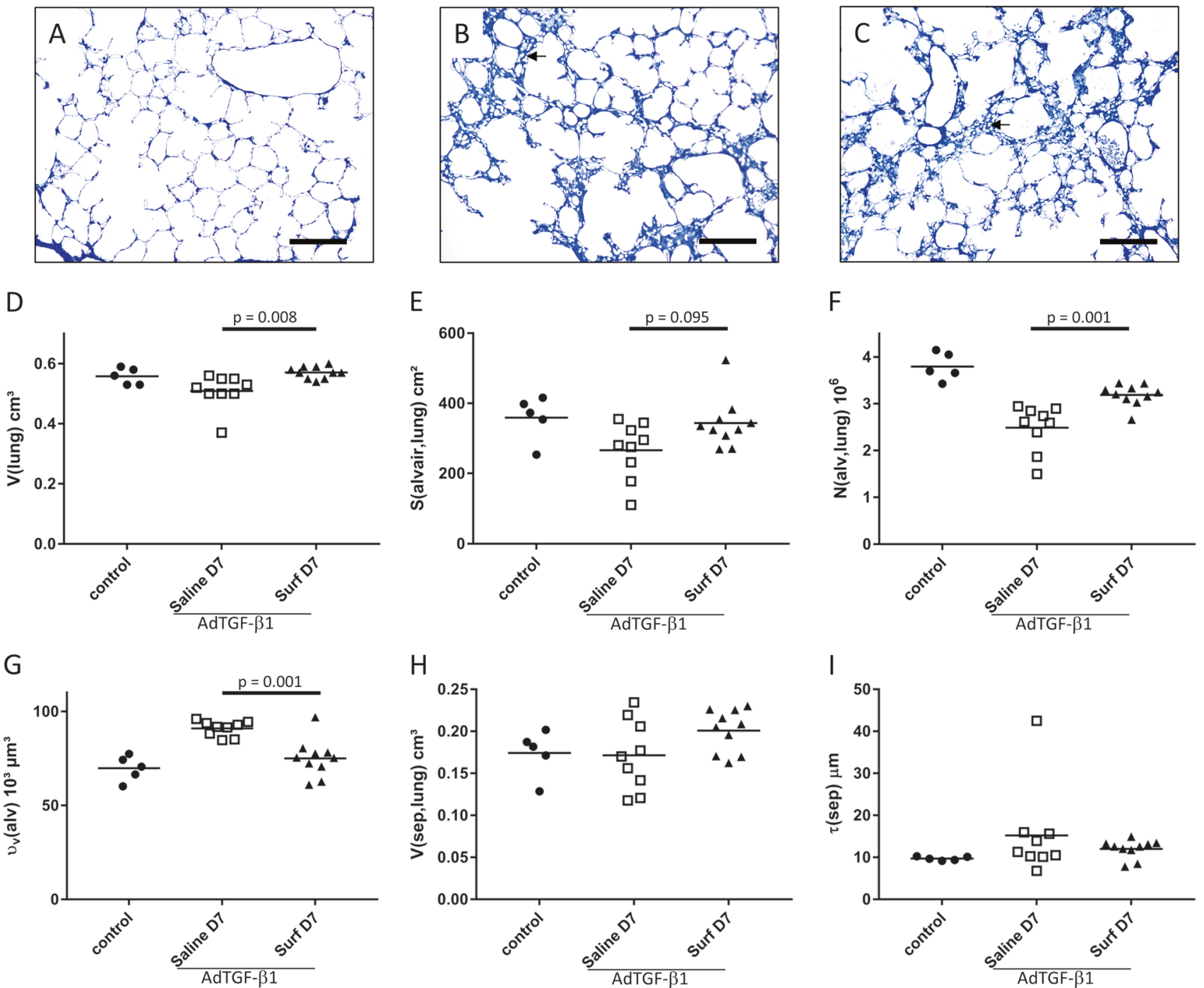

Fig. 2 Alveolar microarchitecture on D7. Representative light microscopic images of healthy control (a), Saline D7 (b), and Surf D7 (c). The arrows in $\mathbf{b}$ and $\mathbf{c}$ point to microatelectases. Microatelectases are absent in a. The following parameters are illustrated: total lung volume (d), total surface area of alveoli per lung (e), total number of open alveoli per lung (f), volume-weighted mean volume of alveoli (g), total

\section{Surfactant replacement therapy reduces abnormalities in lung microarchitecture on D7}

At light microscopic level, distal airspaces were inflated in healthy controls and most of the capillaries in the septal walls were free of blood cells, indicating that perfusion fixation at the given airway opening pressure of $5 \mathrm{cmH}_{2} \mathrm{O}$ was successful. Microatelectases were completely absent under healthy conditions (Fig. 2a). In some areas of the lung, microatelectases were observed in Saline D7 (Fig. 2b) as well as Surf D7 (Fig. 2c). Such findings were accompanied by enlarged ductal airspaces and occasionally small amounts of alveolar edema fluid while inflammatory infiltrates were uncommon. At a qualitative level, no clear volume of septal walls per lung (h), and arithmetic mean thickness of septal walls (i). Data in $\mathbf{d}$ to $\mathbf{i}$ show individual data and mean of stereological parameters determined at light microscopic level. AdTGF- $\beta 1$ : adenoviral vector-mediated gene transfer of active TGF$\beta 1$. Scale bar in $\mathbf{a}-\mathbf{c}: 100 \mu \mathrm{m}$

differences could be discerned between Surf and Saline at this time point and pathological alterations were present in both groups.

Hence, a design-based stereological analysis was performed and data characterizing alveolar microarchitecture are given in Fig. 2d-i. Comparing Saline and Surf on D7 demonstrated a significantly larger lung volume ( $V$ (lung)) in the Surf group (Fig. 2d). However, no significant differences between Saline and Surf were observed regarding total volumes of acinar airspaces per lung (V(acinair,lung)), which encompass both alveolar and ductal airspaces taken together [mean (SD): $0.24(0.07) \mathrm{cm}^{3}$ vs. $0.28(0.02) \mathrm{cm}^{3}$, $p=0.273]$. Nevertheless, the Surf group demonstrated a nonsignificant trend of an increase in the total surface area 
A

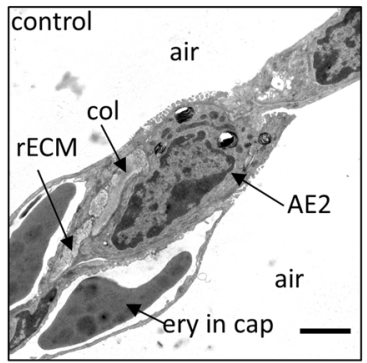

D
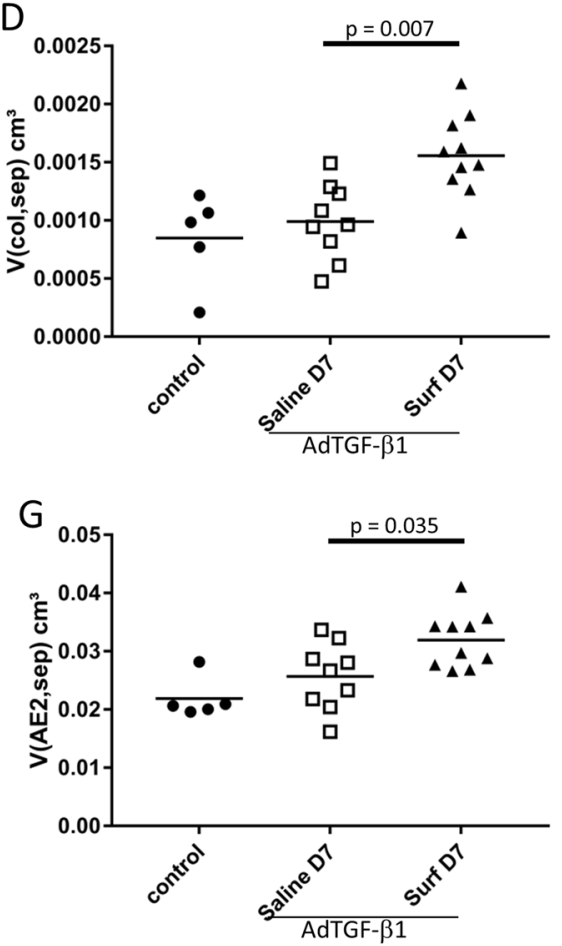

Fig. 3 Composition of lung parenchyma on D7. Electron microscopic images are presented from healthy control (a), Saline D7 (b), and Surf D7 (c). Stereological data obtained at electron microscopical level are given in $\mathbf{d}$ to $\mathbf{i}$ and show total volume of collagen fibrils within septal walls (d), total volume of extracellular matrix components other than collagen fibrils within septal walls (e), total volume of interstitial cells within septal walls (f), total volume of alveolar epithelial type 2 cells within septal walls (g), total volume of lamellar bodies per lung (h),

of air covered alveolar walls (Fig. 2e, S(alvair,lung)), a finding that was in line with the observation that the number of open alveoli was significantly increased in Surf compared with Saline at D7 (Fig. 2f, $N($ alv,lung)). Using the total volume of alveolar airspaces per lung and the number of open alveoli, the number-weighted mean volume of alveoli was calculated corresponding to the mean of the intraindividual size distribution of alveoli. The number-weighted mean volume of alveoli $\left(\nu_{\mathrm{N}}(\mathrm{alv})\right)$ did not demonstrate a significant difference between Saline D7 and Surf D7 [mean (SD): 57.7 (11.8) $10^{3} \mu \mathrm{m}^{3}$ vs. $52.0 \quad$ (4.6) $10^{3} \mu \mathrm{m}^{3}$; $p=0.388]$. In addition, the point sampled intercept method was used to determine the volume-weighted mean volume
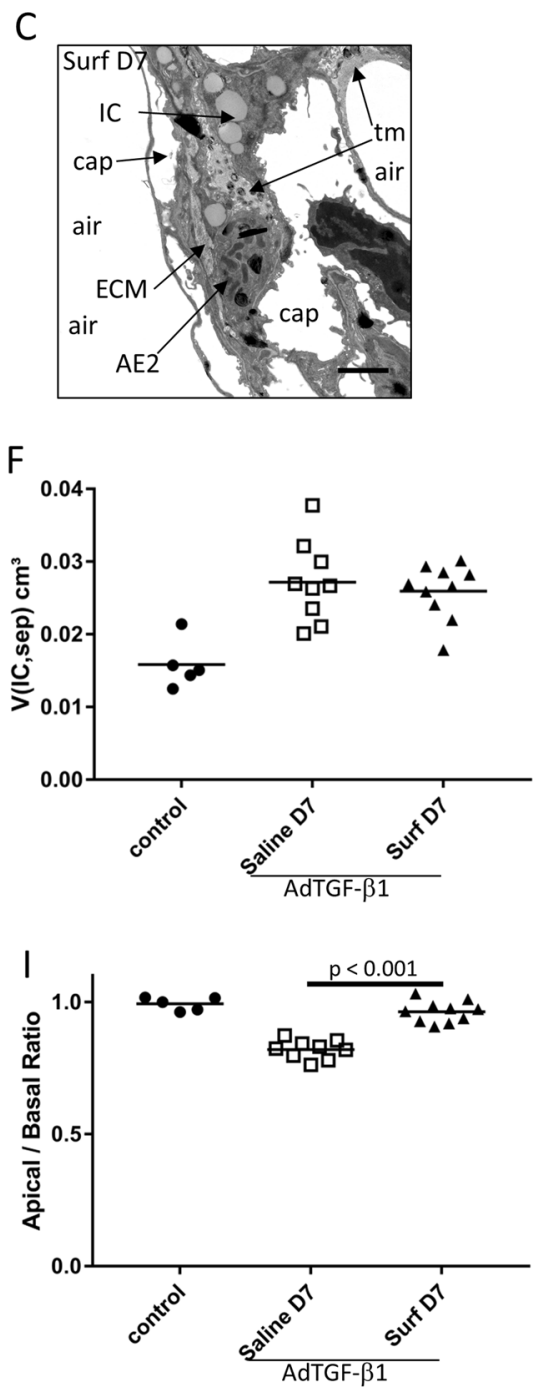

and the ratio of the surface area of the apical and baso-lateral membrane of alveolar epithelial type 2 cells (i). Individual data and mean are presented. Scale bar in a-c: $2 \mu \mathrm{m}$. Abbreviations: air: distal airspace; col: collagen fibrils; rECM: extracellular matrix other than collagen fibrils; AE2: alveolar epithelial type 2 cell; ery: erythrocyte; cap: capillary lumen; IC: interstitial cells; tm: tubular myelin. AdTGF$\beta 1$ : adenoviral vector mediated gene transfer of active TGF- $\beta 1$

of alveoli $\left(\nu_{\mathrm{V}}(\mathrm{alv})\right)$, where significantly higher values could be found in Saline D7 compared with Surf D7 (Fig. 2g). Using the point-sampled intercept method, larger alveoli have a higher probability of being measured so that the volume-weighted mean volume over-represents larger alveoli and therefore is not only dependent on the "real" mean of the alveolar size distribution within an individual (= number-weighted mean volume) but also depends on the size variability. In other words, the larger the alveolar size variability the larger the volume-weighted mean volume. Hence, the increased volume-weighted mean alveolar volume in Saline D7 compared with Surf D7 results from an increased alveolar size variability $(=\mathrm{SD}$ of 
Table 3 Structure-function relationship at D7

\begin{tabular}{|c|c|c|c|c|c|c|c|c|c|c|c|c|c|}
\hline & & $\begin{array}{l}V \text { (alvair, } \\
\text { lung) }\end{array}$ & $\begin{array}{l}V(\text { sept, } \\
\text { lung) }\end{array}$ & $\begin{array}{l}S \text { (alvair, } \\
\text { lung) }\end{array}$ & $\tau(\mathrm{sep})$ & $\begin{array}{l}N(\text { alv, } \\
\text { lung) }\end{array}$ & $\nu_{\mathrm{N}}(\mathrm{alv})$ & $\nu_{\mathrm{V}}($ alv $)$ & $\begin{array}{l}V(\mathrm{col}, \\
\text { sep) }\end{array}$ & $\begin{array}{l}V(\mathrm{rECM}, \\
\text { sep })\end{array}$ & $V(\mathrm{IC}, \mathrm{sep})$ & $\begin{array}{l}V \text { (alved, } \\
\text { sep) }\end{array}$ & $\begin{array}{l}\text { Apical/ basal } \\
\text { ratio }\end{array}$ \\
\hline \multirow[t]{2}{*}{ Cst } & $r$ & 0.613 & 0.017 & 0.666 & -0.620 & 0.749 & -0.202 & -0.436 & -0.119 & -0.016 & -0.484 & -0.377 & 0.472 \\
\hline & $p$ & 0.002 & 0.939 & 0.001 & 0.002 & 0.000 & 0.356 & 0.038 & 0.590 & 0.943 & 0.019 & 0.076 & 0.023 \\
\hline \multirow[t]{2}{*}{$\mathrm{H}$} & $r$ & -0.679 & 0.047 & -0.640 & 0.637 & -0.693 & 0.121 & 0.376 & 0.043 & -0.084 & 0.508 & 0.303 & 0.449 \\
\hline & $p$ & $<0.001$ & 0.830 & 0.001 & 0.001 & $<0.001$ & 0.584 & 0.077 & 0.844 & 0.703 & 0.013 & 0.159 & 0.032 \\
\hline
\end{tabular}

the distribution of alveolar sizes, $\left.\mathrm{SD}\left(\nu_{\mathrm{X}}(\mathrm{alv})\right)\right)$. Using number and volume-weighted mean volume of alveoli, the $\mathrm{CV}$ and at the end SD $\left(\nu_{\mathrm{X}}(\mathrm{alv})\right)$ for each lung were calculated. The group's mean and SD of control, Saline D7, and Surf D7 were $30.6(4.5) 10^{3} \mu^{3}, 41.6(7.2) 10^{3} \mu^{3}$ and $33.7(7.5) \mu \mathrm{m}^{3}$, respectively. Saline D7 had significantly higher values compared with control $(p=0.029)$, whereas Surf D7 showed a nonsignificant trend for reduced SD $\left(\nu_{\mathrm{X}}\right.$ (alv)) values compared with Saline D7 $(p=0.062)$. Considering the septal walls, neither their total volume per lung (Fig. 2h, V(sep,lung)) nor their arithmetic mean thickness (Fig. 2i, $\tau($ sep)) differed between Saline and Surf on D7.

At electron microscopic level, the impression from light microscopic imaging that alveolar walls were piled up due to microatelectases was supported. In both Saline D7 and Surf D7, AE2 cells and epithelial cells of the opposing septal wall were often nearly touching so that it appeared that AE2 cells were completely surrounded by capillaries without contact to the airspace (Fig. 3b and c). In the Surf group, intra-alveolar surfactant components such as tubular myelin or lamellar body-like structures were frequently observed, in particular in the corners of alveoli (Fig. 3c). In a further step, the composition of the septal walls was quantified by design-based stereology and data are summarized in Fig. 3d-i. Regarding the interstitial tissue, the volume of collagen fibrils within alveolar septa was slightly but significantly increased in Surf D7 compared with Saline D7 (Fig. 3d, V(col,sep)). In addition, within septal walls the volume of ECM components other than collagen fibrils ( = residual ECM, rECM) were also increased in Surf D7 (Fig. 3e, $V($ rECM,sep)). However, within the septal wall tissue, no differences between Saline and Surf groups regarding the volumes of interstitial cells (Fig. 3f, V(IC, sep)), the endothelial cells [ $V($ endo,sep), mean (SD): 28.4 (3.9) $\mathrm{mm}^{3}$ vs. $30.1(9.9) \mathrm{mm}^{3}, p=0.939$ ] or the capillary lumen [V(caplumen,sep), mean (SD): $64.4(18.7) \mathrm{mm}^{3}$ vs. $\left.84.3(16.8) \mathrm{mm}^{3}, p=0.077\right]$ were observed. Of note, the volumes of endothelial cells and the capillary lumen taken together ( = capillary network of septal walls) contributed with more than $50 \%$ to the septal wall volume in all study groups. As AE2 cells are involved in the de novo biosynthesis and recycling of surfactant and TGF- $\beta 1$ has been shown to have major effects on AE2 ultrastructure, a more detailed investigation of this cell type was performed. Following surfactant replacement therapy, the total volume of AE2 cells within septal walls was significantly increased in the Surf as compared with the Saline group on D7 (Fig. 3g, $V$ (AE2,lung)). This increased volume of AE2 cells in Surf D7 was, compared with Saline D7 group, at least in part a consequence of a significantly increased volume of lamellar bodies per lung, which is the storing organelle of surfactant exclusively found in AE2 cells (Fig. 3h, V(lb,lung)). As TGF- $\beta 1$ has been shown to reduce the apical membrane surface area in relation to the baso-lateral membrane surface area of AE2 cells, the effect of surfactant replacement therapy on this alteration was investigated. The ratio of the apical to baso-lateral membrane surface areas was significantly larger in the Surf D7 group compared with the Saline D7 group and was in the range of healthy controls (Fig. 3i, Apical/ Basal ratio).

Taken together, on D7 surfactant replacement therapy was effective in preventing alveolar collapse and reducing alveolar size variability. Within the septal walls there was a slight increase of ECM components due to surfactant replacement therapy. Moreover, the volumes of AE2 cells and lamellar bodies were increased and the ratio of the apical to basolateral membrane surface area of AE2 cells was normalized.

\section{Structure-function relationship on D7}

On D7, both static compliance and tissue elastance differed significantly in the Saline group compared with the healthy control, indicating that the gene transfer was efficient and induced abnormalities in lung structures. To understand which structural alterations were linked with lung mechanical abnormalities, pooled structural and lung mechanical data from healthy controls, Saline D7, and Surf D7 were used for correlation analyses, in order to investigate structure-function relationships during an early phase of the model (Table 3). Total volume of alveolar airspaces ( $V$ (alvair,lung)), surface area of air covered alveoli ( $S$ (alvair, lung)), and number of open alveoli ( $N($ alv,lung)) demonstrated strong positive correlations with quasi-static 

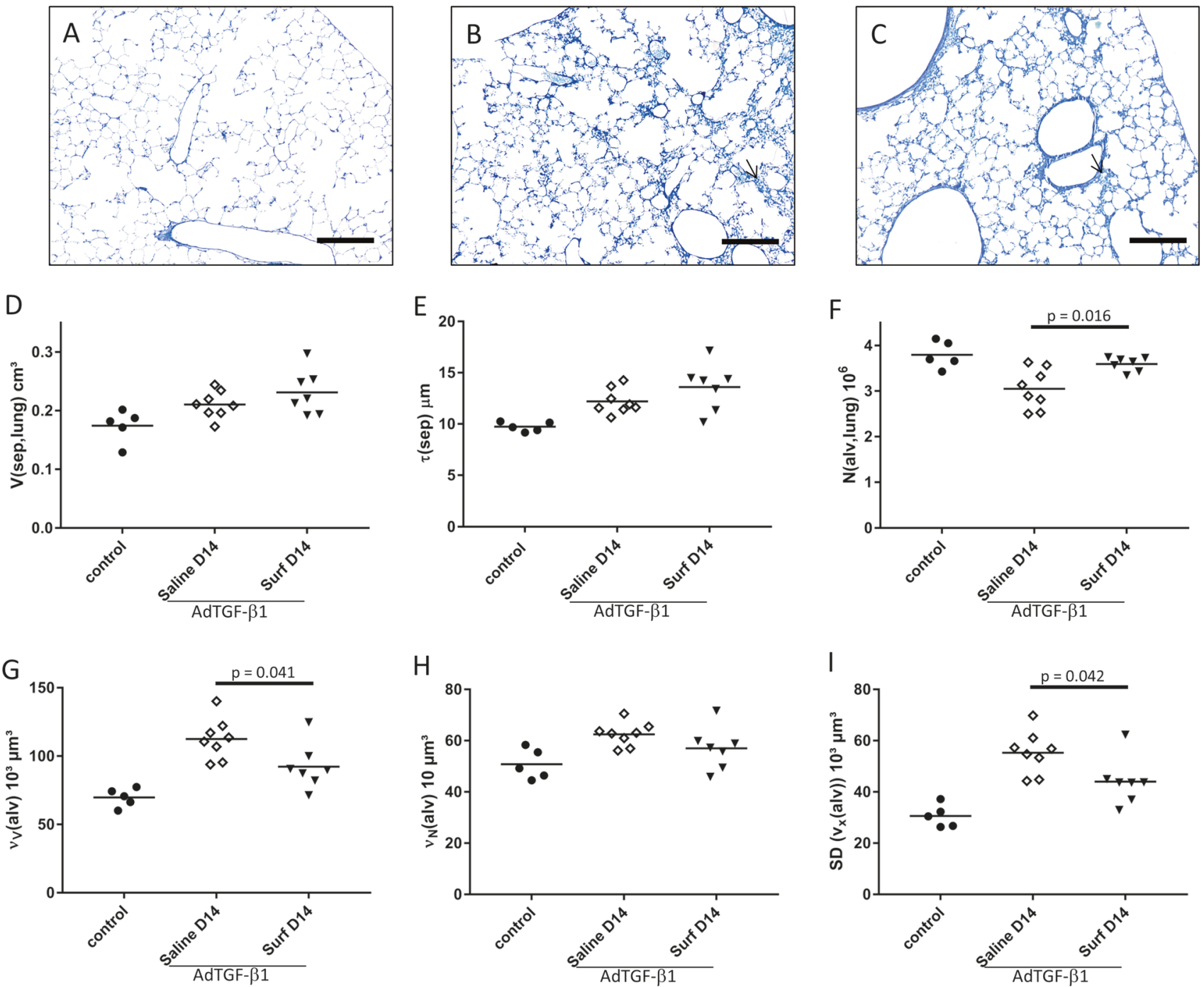

Fig. 4 Alveolar microarchitecture on D14. Representative light microscopic images of healthy control (a), Saline D14 (b), and Surf D14 (c). The arrows in $\mathbf{b}$ and $\mathbf{c}$ indicate areas of thickened parenchymatous tissue. The following parameters are illustrated: total volume of septal walls per lung (d), arithmetic mean thickness of septal walls (e), total number of open alveoli per lung (f), volume- weighted mean volume of alveoli (g), number-weighted mean volume of alveoli (h), intraindividual SD of the distribution of alveolar sizes (i). In $\mathbf{d}$ to $\mathbf{i}$ stereological data are presented as individual values and mean. AdTGF- $\beta 1$ : adenoviral vector mediated gene transfer of active TGF- $\beta 1$. Scale bar in a-c: $200 \mu \mathrm{m}$

Taken together, surfactant replacement therapy stabilized alveoli. Structural parameters reflecting stable alveoli, in particular the number of open alveoli, showed the strongest correlations with lung mechanical properties on D7.

\section{Surfactant replacement therapy prevents alveolar collapse and alveolar size heterogeneity on D14}

Compared with healthy controls, both Saline and Surf demonstrated in some areas of the lung thickened septal walls and also signs of persisting microatelectases at light microscopic level at D14 (Fig. 4a-c). However, a clear 
A
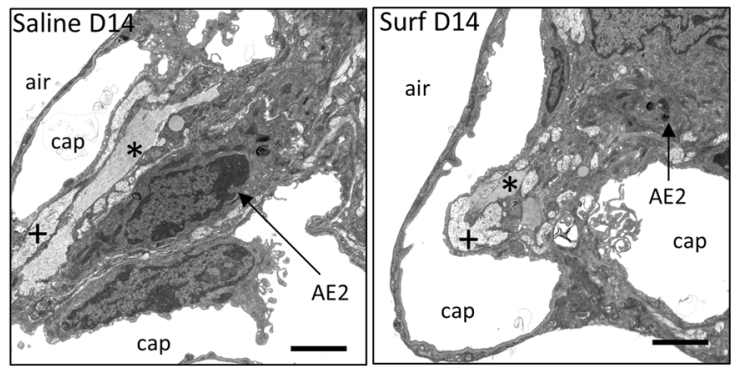

B

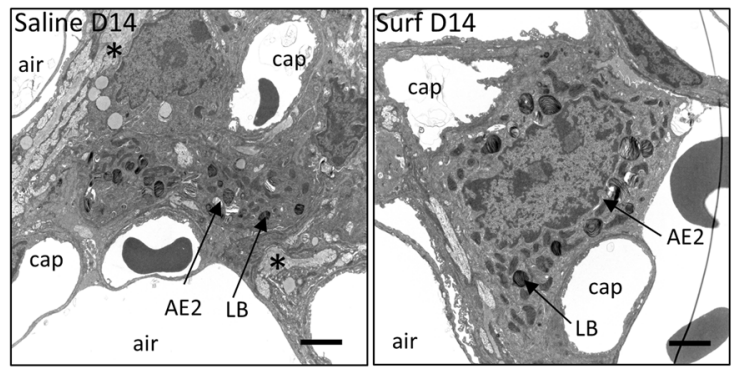

C

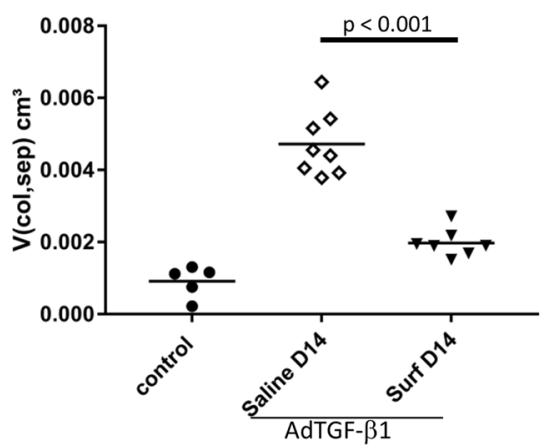

$\mathrm{F}$

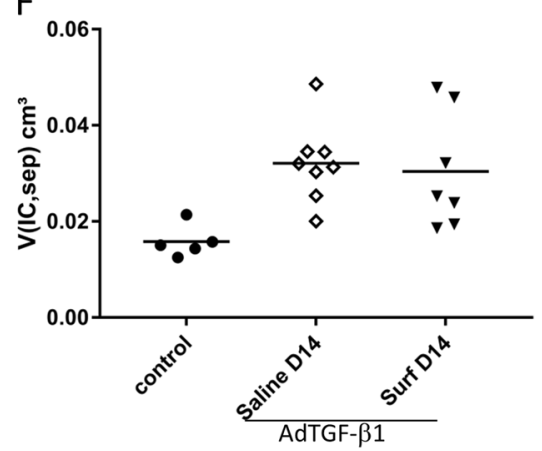

D

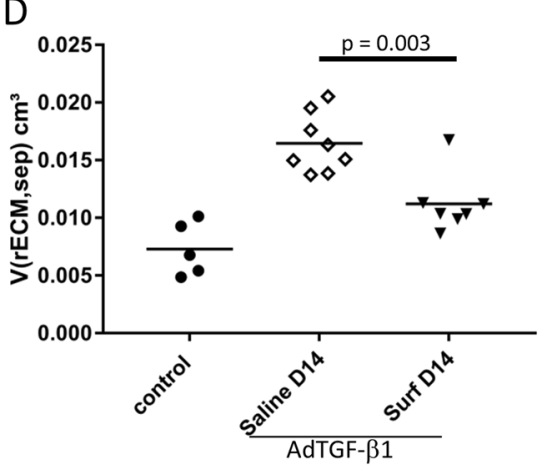

G

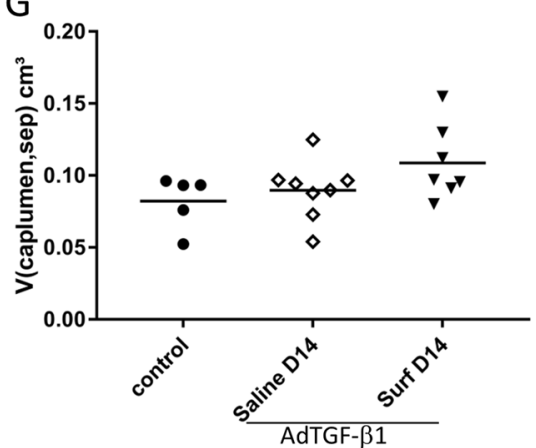

$E$

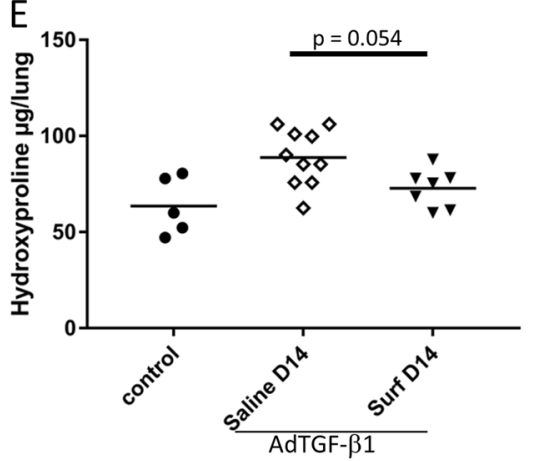

$\mathrm{H}$

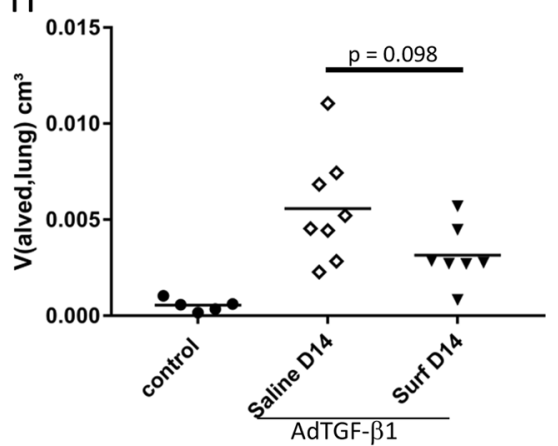

Fig. 5 Surfactant replacement therapy and septal wall remodeling. In a, representative ultrastructural findings regarding the composition of septal walls are depicted. In both Saline D14 and Surf D14, the amount of collagen fibrils $(*)$ and residual ECM $(+)$ seem to be higher as compared to the healthy control in Fig. 3a. In the center of the septa and surrounded by capillaries, profiles of lamellar body containing cells are visible (AE2). In $\mathbf{b}$, further examples of AE2 cells are illustrated and the size and number of lamellar bodies (LB) appear to be higher in the Surf D14 example. Of note, lamellar body containing cells within the alveolar septa are often colocalized with increased volumes of ECM components (*collagen fibrils + rECM). The following parameters are visualized: total volume of collagen fibrils within septal walls (c), total volume of extracellular matrix components other than collagen fibrils within septal walls (d), the hydroxyproline level per lung (e), total volume of interstitial cells within septal walls (f), the total volume of capillary lumen within septal walls (g), and the total volume of alveolar fluid/edema (h). With the exception of e, electron microscopically obtained stereological data characterizing the composition of the septa are given in $\mathbf{c}-\mathbf{h}$. Individual data and mean are given in $\mathbf{c}-\mathbf{h}$. AdTGF- $\beta 1$ : adenoviral vector mediated gene transfer of active TGF- $\beta 1$. Scale bar in a and $\mathbf{b}: 2 \mu \mathrm{m}$. Abbreviations: air: distal airspace, cap: capillary lumen, AE2: alveolar epithelial type 2 cell, LB: lamellar body difference between the Saline D14 and Surf D14 could not be discerned (Fig. 4b and c). The stereological data did not show statistically significant differences regarding volumes of acinar airspaces per lung [ $V$ (acinair,lung), mean (SD): $0.29(0.03) \mathrm{cm}^{3}$ vs. $\left.0.32\left(0.05 \mathrm{~cm}^{3}\right), p=0.333\right]$ or septal wall tissue (Fig. 4d, V(sep,lung)), as well as arithmetic mean thickness of septal walls (Fig. 4e, $\tau($ sep)) between Saline and Surf. However, although there was no difference regarding the total surface area of air covered alveolar walls between Saline and Surf [S(alvair,lung), mean (SD): 346 (34) $\mathrm{cm}^{2}$ vs. $\left.341(26) \mathrm{cm}^{2}, p=0.683\right]$, there was a slight and significant increase in the number of open alveoli in the Surf compared with the Saline group (Fig. 4f, $N$ (alv,lung)). Also, the volume-weighted mean volume of alveoli differed significantly between Saline and Surf with lower values found in Surf (Fig. $\left.4 \mathrm{~g}, \nu_{\mathrm{V}}(\mathrm{alv})\right)$. The differences in the 

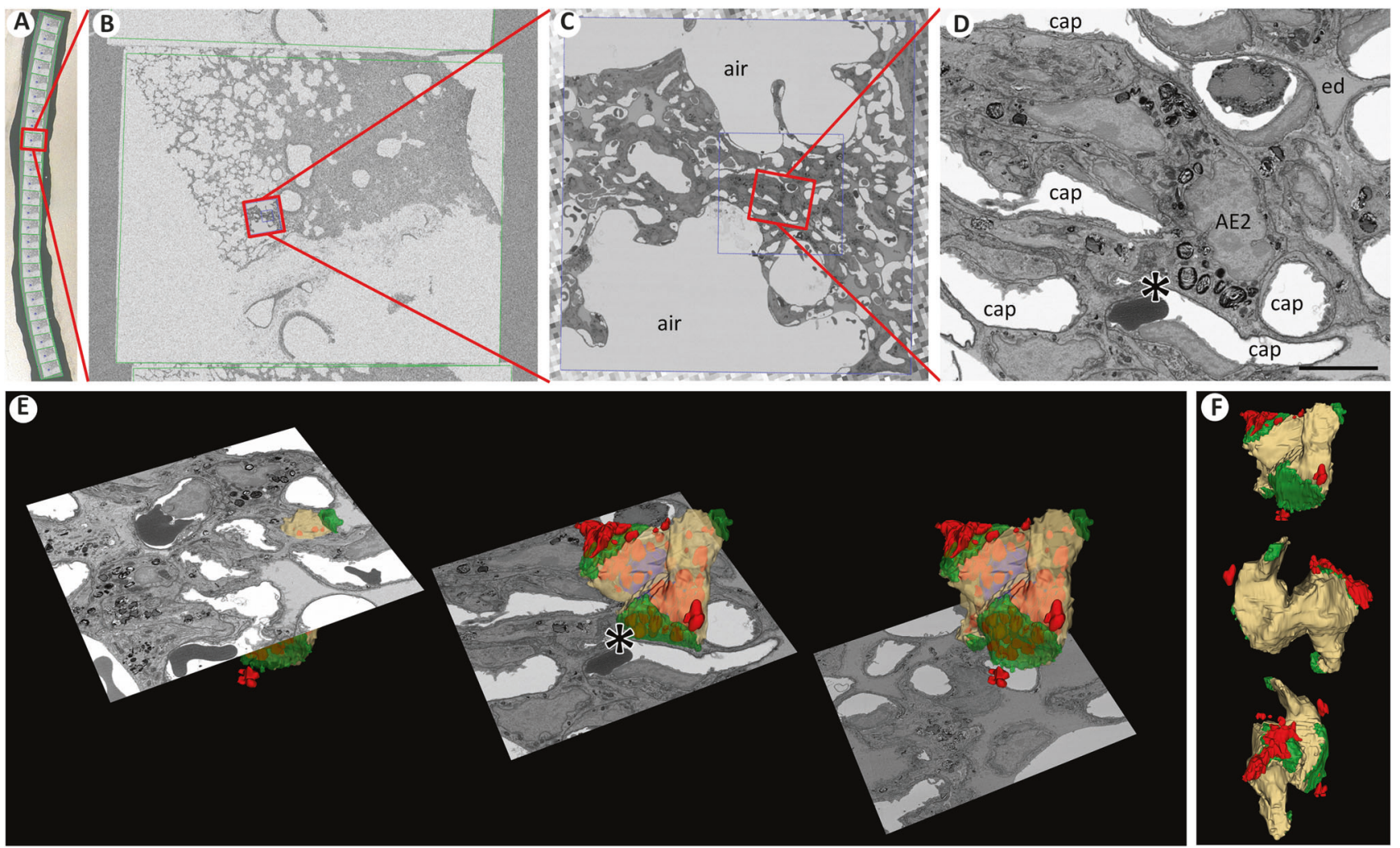

Fig. $63 \mathrm{D}$ analysis of an AE2 cell showing no contact to alveolar airspace in a 2D section (d). Correlative light microscopy with SEM array tomography was used to locate and reconstruct a region of interest in 3D. About 665 sections were analyzed by light microscopy and the identified ROI was scanned with SEM at high resolution (a: sections on microscope slide; b-d ascending magnifications and resolutions of ROI). Image D: AE2 cell of interest in 2D (asterisk; scale bar: $5 \mu \mathrm{m}$ ). Model of reconstructed AE2 cell is depicted with

number-weighted mean volume of alveoli were, however, not significant (Fig. 4h, $\nu_{\mathrm{N}}($ alv $)$ ). As the volume-weighted mean volume depends on both the number-weighted mean volume as well as the intra-individual size variability, the intra-individual SD of alveolar sizes $\left(\nu_{\mathrm{X}}(\mathrm{alv})\right)$ was calculated. The SDs of intra-individual alveolar volumes were largest in Saline D14 and were significantly reduced in Surf D14 (Fig. 4i, SD $\nu_{\mathrm{X}}($ alv)).

In essence, surfactant replacement therapy during the first week after TGF- $\beta 1$ gene transfer resulted in a persisting increase in alveolar number with decreased alveolar size heterogeneity at D14, a time point at which fibrotic remodeling can already be detected. Hence, in a further step, the composition of the interstitial tissue of the septal walls was investigated.

\section{Surfactant replacement therapy and septal wall remodeling on D14}

At electron microscopic level, a lot of interstitial cells and components of the ECM including collagen fibrils could be tissue context in three z-layers (e); asterisk indicates the same position in $\mathbf{d}$ and $\mathbf{e}$; baso-lateral plasma membrane (beige), apical plasma membrane (green), nucleus (blue), lamellar bodies, and lamellar-body like structures (red). The AE2 cell had no exposure to the air spaceonly contact with edema fluid was existent. The AE2 cell model is shown in different orientations (f). Abbreviations: air: distal airspace, cap: capillary lumen, AE2: alveolar epithelial type 2 cell, ed: alveolar edema fluid

observed in Surf as well as Saline (Fig. 5a and b), whereas in healthy controls collagen fibrils and interstitial cells represented a minor fraction of the septal walls (Fig. 3a). In analogy to D7, AE2 cells completely surrounded by lung parenchyma could still be found at D14 in particular in the Saline group (Fig. 5a and b). Such profiles of AE2 cells embedded in tissue and completely surrounded by the basal lamina were often seen in colocalization with areas showing deposition of abundant collagen fibrils (Fig. 5a). However, whereas no differences of total septal wall volumes per lung as well as the arithmetic mean thickness of septal walls could be observed between Surf and Saline (Fig. 4d and e), unbiased stereological analyses of the septal walls demonstrated significant differences regarding the composition of septal walls. The absolute volume of ECM within the septal walls $(V(\mathrm{ECM}$,sep $))$ was significantly higher in Saline compared with Surf at D14 [mean (SD): $16.5(2.5) \mathrm{mm}^{3}$ vs. $\left.11.2(2.6) \mathrm{mm}^{3}, p<0.001\right]$. At ultrastructural level, the ECM could be separated into collagen fibrils and the residual ECM (other than collagen fibrils). The rECM encompassed elastic fibers, epithelial and endothelial basal 
Fig. 7 Stereological data of AE2 cell alterations at D14. The following parameters are visualized: total volume of AE2 cells within septal walls (a), total volume of lamellar bodies within septal walls $(\mathbf{b})$, total surface area of the apical membrane of AE2 cells per lung (c), and the ratio of the surface area of the apical and basolateral membrane of AE2 cells (d). Mean and individual data are illustrated in $\mathbf{a}-\mathbf{d}$. AdTGF$\beta 1$ : adenoviral vector mediated gene transfer of active TGF- $\beta 1$
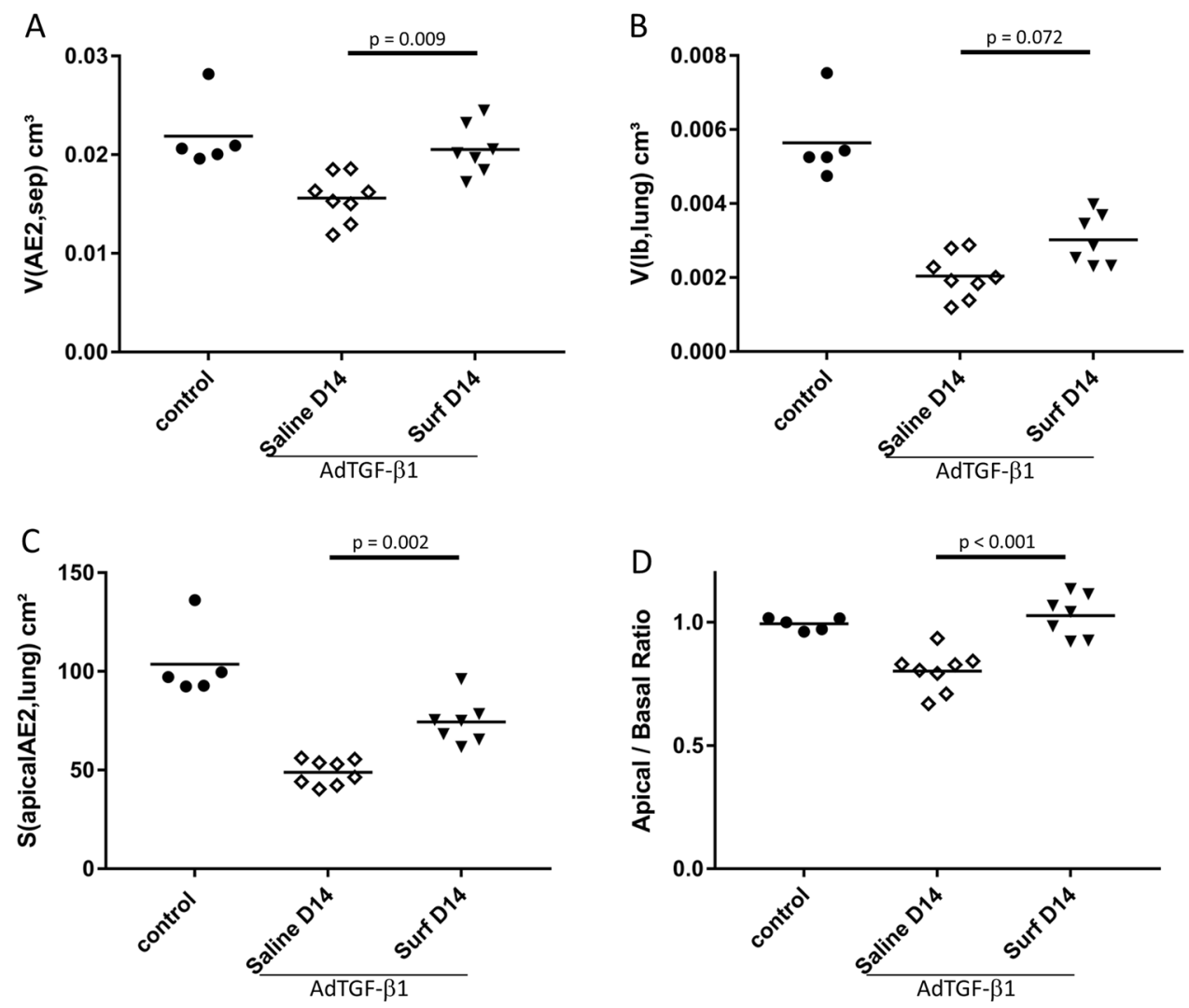

laminae, and amorphous ECM. Both the volume of collagen fibrils and the volume of residual ECM demonstrated a highly significant reduction in Surf compared to Saline (Fig. 5c, d). In line with this observation, the hydroxyproline level per lung demonstrated a nonsignificant trend for lower values in Surf compared with Saline (Fig. 5e). However, the extent of differences between Surf and Saline was not that obvious based on the hydroxyproline, which showed a reduction of the mean from approximately 90-70 $\mu \mathrm{g}$ per lung compared with the structural data of collagen fibrils, which were reduced from approximately $5-2 \mathrm{~mm}^{3}$ per lung (Fig. 5c). The stereological analyses concentrated on the collagen fibrils in the septal walls and did not take structures into account, which usually contribute most of the lung collagen such as walls of conducting airway or larger blood vessels, and the perivascular and peribronchiolar connective tissue. All these structures that usually contribute lung collagen, however, are not part of fine lung parenchyma in which gas exchange takes place. Within lung parenchyma, the collagen fibrils contribute only $0.5 \%$ to the volume of septal walls. The hydroxyproline level, however, does not distinguish between lung parenchyma and non-parenchyma so that changes occurring in the septal walls might be blurred. Unlike collagen content, there were no significant differences regarding the volumes of interstitial cells (Fig. 5f, V(IC,sep)), endothelial cells [V(endo, sep, mean (SD): $26.3(2.6) \mathrm{mm}^{3}$ vs. $30.6(3.9) \mathrm{mm}^{3}$ ] or the capillary lumen (Fig. 5g, V(caplumen,sep)) between Saline and Surf on D14. The mean and SD of the surface area of endothelial cells within septal walls ( $S$ (endo,sep) were 1133 (152) $\mathrm{cm}^{2}$ vs. $1186(175) \mathrm{cm}^{2}$ vs. $1253(92) \mathrm{cm}^{2}$ for healthy control, Saline D14, and Surf D14, respectively, without significant differences between study groups. The absolute volume of alveolar edema fluid per lung demonstrated a nonsignificant trend in favor of the Surf D14 in comparison with Saline D14 (Fig. 5h, V(alved,lung)).

Taken together, although the septal wall thickness and the total volume of septal walls per lung did not differ significantly between Surf and Saline on D14, the composition of the septal walls demonstrated effects of surfactant replacement therapy; although interstitial cellular components were unaffected in this model, the total volume of ECM and in particular the collagen fibrils were significantly reduced.

\section{Ultrastructure of AE2 cells on D14}

Data regarding the electron microscopic assessment of the alveolar epithelium are illustrated in Figs. 5-7. Within thickened septal walls, profiles of AE2 cells were observed in Saline-treated fibrotic lungs but also in the Surf group (Figs. 5a, b and 6). Quite often, these AE2 cells did not 
Table 4 Structure-function relationship at D14

\begin{tabular}{|c|c|c|c|c|c|c|c|c|c|c|c|c|c|}
\hline & & $\begin{array}{l}V \text { (alvair, } \\
\text { lung) }\end{array}$ & $\begin{array}{l}V(\text { sept, } \\
\text { lung) }\end{array}$ & $\begin{array}{l}S \text { (alvair, } \\
\text { lung) }\end{array}$ & $\tau(\mathrm{sep})$ & $\begin{array}{l}N(\text { alv, } \\
\text { lung) }\end{array}$ & $\nu_{\mathrm{N}}(\mathrm{alv})$ & $\nu_{\mathrm{V}}($ alv $)$ & $\begin{array}{l}V(\mathrm{col}, \\
\text { sep) }\end{array}$ & $\begin{array}{l}V(\mathrm{rECM}, \\
\text { sep) }\end{array}$ & $V(\mathrm{IC}, \mathrm{sep})$ & $\begin{array}{l}V(\text { alved, } \\
\text { sep) }\end{array}$ & $\begin{array}{l}S(\text { apical, } \\
\text { AE2) }\end{array}$ \\
\hline \multirow[t]{2}{*}{ Cst } & $r$ & 0.185 & -0.376 & 0.095 & -0.469 & 0.525 & -0.550 & -0.582 & -0.865 & -0.687 & -0.565 & $-0.513^{*}$ & $0.800^{* *}$ \\
\hline & $p$ & 0.435 & 0.102 & 0.691 & 0.037 & 0.018 & 0.012 & 0.007 & $>0.001$ & 0.001 & 0.009 & 0.021 & $>0.001$ \\
\hline \multirow[t]{2}{*}{$\mathrm{H}$} & $r$ & -0.077 & 0.391 & -0.125 & 0.468 & -0.605 & 0.672 & 0.556 & 0.785 & 0.621 & 0.561 & 0.444 & -0.702 \\
\hline & $p$ & 0.748 & 0.088 & 0.600 & 0.038 & 0.005 & 0.001 & 0.011 & 0.000 & 0.003 & 0.010 & 0.050 & 0.001 \\
\hline
\end{tabular}

appear to have contact to the lumen of the airspaces and were entirely surrounded by the basal lamina so that no apical cellular membrane was visible. In order to understand whether these cells were still in contact with the airspace, a 3D reconstruction, based on SEM array tomography, was performed (Fig. 6 and video in the Supplementary Materials). The $3 \mathrm{D}$ reconstruction revealed that such cells had a complex structure. The apical membrane was in contact with three to four slender lacunae which were completely filled with electron dense edema fluid and most likely represent collapsed distal airspaces. Within the edema-filled lacunae, lamellar-body-like structures were observed, indicating that exocytosis took place. However, the lamellarbody-like structures were far away from the airspaces of un-collapsed alveoli and tubular myelin, which usually develops when the lipid membranes of the lamellar-bodylike structures unwrap in the hypophase [47]. Taken together, these $3 \mathrm{D}$ reconstructions illustrate that there are AE2 cells that are not functional, as they do not have any contact to the airspace, and that the secreted surfactant seems to be trapped in collapsed alveoli that form edemafilled lacunae.

The stereological data regarding AE2 cells are illustrated in Fig. 7. Compared with Saline, the total volume of AE2 cells per lung was significantly larger in the Surf group (Fig. 7a, V(AE2,sep)). The total volume of intracellular surfactant, defined as the total volume of lamellar bodies per lung (V(lb,lung)), demonstrated a nonsignificant trend to increased values in Surf D14 compared with Saline D14 (Fig. 7b). The total volume of tubular myelin, which usually represents the reservoir of surfactant in the hypophase of the alveolar space, was significantly lower in Saline D14 [mean (SD): $0.80(0.63) \mathrm{mm}^{3}$ ] compared with Surf D14 [mean (SD): $\left.2.44(0.41) \mathrm{mm}^{3}, p<0.001\right]$. Moreover, the surface area of the apical membrane of AE2 cells per lung was larger (Fig. 7c, S(apicalAE2,lung)) and the ratio of the surface area of the apical membrane and the basolateral membrane of AE2 cells was normalized in Surf compared with Saline (Fig. 7d, Apical/basal ratio).

Taken together, abnormal loss of apical membrane surface area of AE2 cells could be attenuated and the volume of tubular myelin, an active component of intra-alveolar surfactant, increased by surfactant replacement therapy during the first week.

\section{Structure-function relationship on D14}

Quasi-static compliance (Cst) was significantly inferior in the Saline D14 group compared with the healthy control $(p=0.001)$, whereas tissue elastance $H$ showed at best a non-significant trend $(p=0.10)$. On the other hand, Cst $(p=0.584)$ and $H(p=0.981)$ did not differ between healthy controls and Surf D14. In order to understand which structural components might be linked to the lung mechanical properties, correlation analyses were performed. Data are summarized in Table 4. Unlike the situation at D7, components of the interstitial tissue had a much stronger correlation to lung mechanical impaiment at D14. Hence, the total volume of collagen ( $V($ col,sep)), rECM ( $V(\mathrm{rECM}$, sep), and interstitial cells ( $V($ IC,sep)) within the septal walls demonstrated strong inverse correlations to Cst and positive correlations to $H$. The apical membrane surface area of AE2 cells per lung ( $S$ (apicalAE2,lung)) demonstrated the other way round a strong positive correlation to Cst and an inverse correlation to $H$. Structural parameters related to the light microscopic lung architecture such as arithmetic mean septal wall thickness ( $t$ (sep)), number of open alveoli per lung $(N($ alv,lung $))$, number $\left(\nu_{\mathrm{N}}(\mathrm{alv})\right)$ and volume-weighted $\left(\nu_{\mathrm{V}}(\mathrm{alv})\right)$ mean volume of alveoli also correlated significantly with lung mechanical properties.

\section{Alveolar collapse: effects on lung mechanics and septal wall remodeling?}

Microatelectases and therefore the loss of alveoli due to collapse is a very prominent observation in animal models of lung injury and fibrosis including the TGF- $\beta 1$ model analyzed in the present study. Taking all five study groups into account, the number of open alveoli strongly inversely correlated with tissue elastance $H$ (Fig. 8a) and positively correlated with quasi-static compliance Cst (Fig. 8b). Hence, alveolar instability is crucial for lung mechanical degradation in this model. Moreover, as microatelectases have been suggested as representing initial triggers for 
A

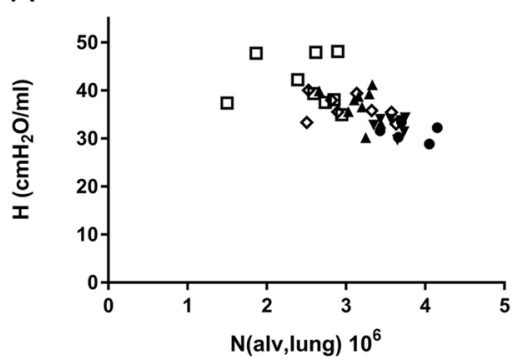

C

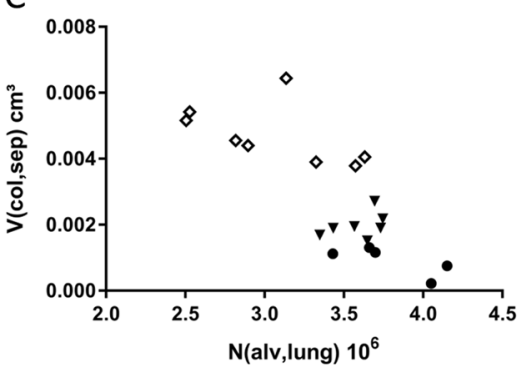

E

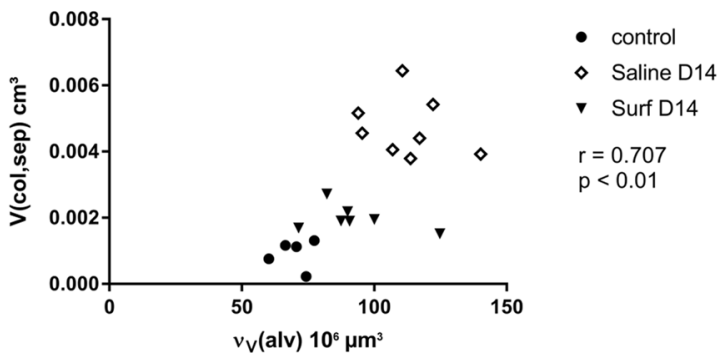

Fig. 8 Correlation analyses between alveolar microarchitecture, lung mechanics, and remodeling. Abnormal alveolar microarchitecture is linked with lung mechanical impairment regarding tissue elastance (a) and quasistatic compliance (b). At D14, abnormal alveolar

fibrotic remodeling, correlation analyses of data from D14, a time point at which fibrotic remodeling has been documented, were performed, in order to describe a relationship between alveolar microarchitecture analyzed at light microscopic level and septal wall remodeling characterized at electron microscopic level. The results are illustrated in Fig. 8. Among parameters describing alveolar microarchitecture, the number of open alveoli demonstrated the strongest inverse correlations with fibrotic septal wall remodeling characterized by an increase in collagen fibrils (Fig. 8c) and rECM $(r=-0.579, p=0.007)$. Also, changes in the ultrastructure of AE2 cells, such as loss of surface area of apical membrane (Fig. 8d) and volumes of lamellar bodies per lung ( $r=0.654, p=0.002)$, demonstrated correlations with the total number of open alveoli. In this model alveolar instability is linked with alveolar size heterogeneity reflected by the increased volume-weighted mean volume of alveoli $\left(\nu_{\mathrm{V}}(\mathrm{alv})\right)$. Accordingly, the
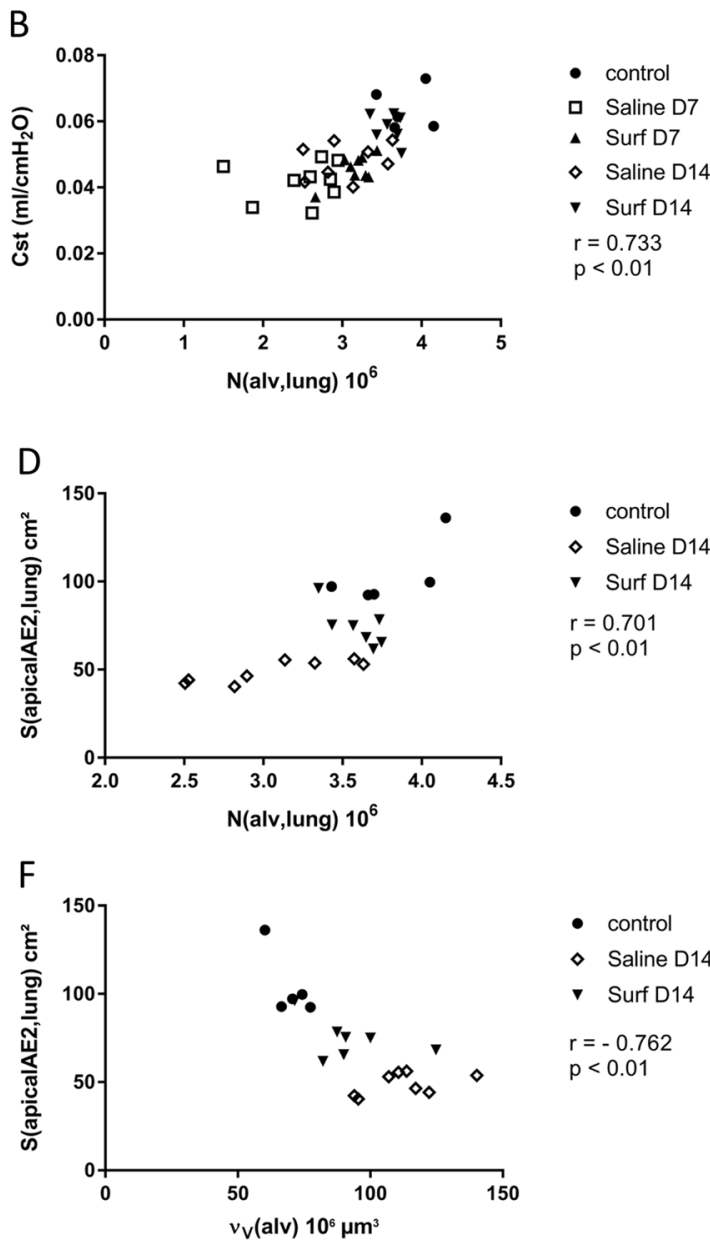

microarchitecture [alveolar number (c, d); volume-weighted mean alveolar volume $(\mathbf{e}, \mathbf{f})$ ] was correlated to the deposition of collagen fibrils in septal wall tissue (c, e) and the decline of the apical membrane surface area of AE2 cells per lung $(\mathbf{d}, \mathbf{f})$

volume-weighted mean volume of alveoli demonstrated convincing correlations to the volume of collagen fibrils (Fig. 8e) and the rECM ( $r=0.651, p=0.002)$. An inverse correlation could be established between the volumeweighted mean volume of alveoli and alterations of AE2 cells such as the apical membrane surface area of AE2 cells per lung (Fig. 8f) and the volume of lamellar bodies per lung $(r=0.729, p<0.001)$.

Taken together, in the TGF- $\beta 1$ mouse model of fibrosis, the degree of alveolar collapse and alveolar size heterogeneity is highly linked to pro-fibrotic interstitial remodeling in alveolar septa as well as alterations of AE2 cells.

\section{AE2 cells in IPF}

In the TGF- $\beta 1$ mouse model, AE2 cells were observed within remodeled and collapsed areas of lung parenchyma and did not have contact to the alveolar airspace. In order to 


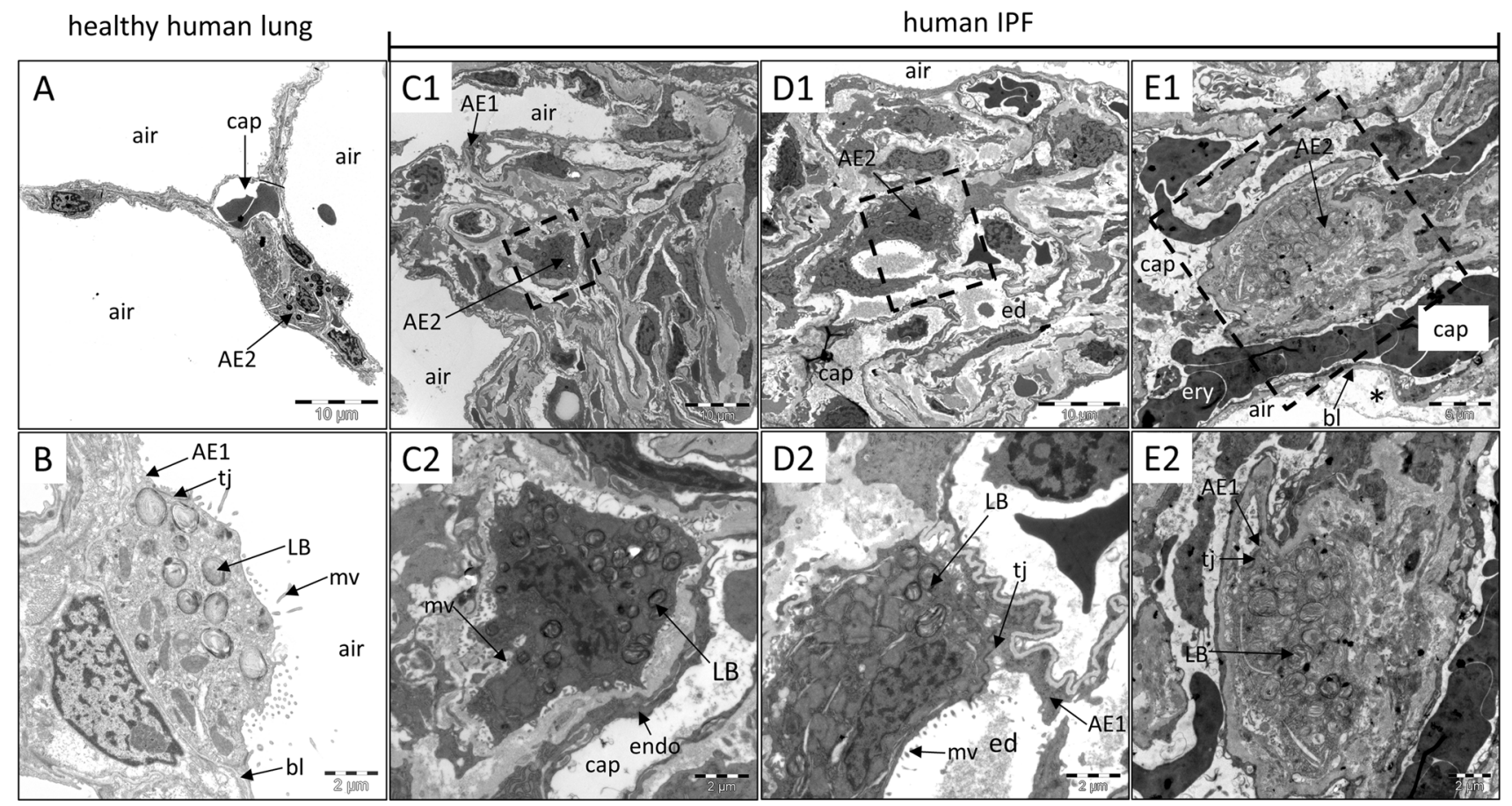

Fig. 9 Ultrastructure of lung tissue from a healthy human (a and $\mathbf{b})$ and human IPF lung explants. Human tissue was taken from previous studies [18, 42]. In a, an overview of a healthy interalveolar septa is shown separating three airspaces from each other. The AE2 cell has contact to two neighboring airspaces. At the junction of three septa, a corner vessel (cap) is visible. In $\mathbf{b}$, a healthy AE2 cell is shown at higher magnification, demonstrating tightly packed lamellar bodies (LB), microvilli (mv), and tight junctions (tj). The mitochondria are not swollen. Within severely remodeled parenchymatous tissue from the IPF lung explant (c-e), lamellar body (LB) containing cells/ alveolar epithelial cells can be identified without contact to the airspace on two-dimensional sections. C1-E1 show overviews. Corresponding C2-E2 depict detail images of these cells. In C1-E1, the rectangle gives an orientation where corresponding detail images were taken from. Besides LB, microvilli (mv) can also be observed in C2. In $\mathrm{D} 2$, the AE2 cell forms a tight junction (tj) with an alveolar epithelial type 1 (AE1) cell. The apical membrane can be identified by the presence of microvilli (mv), directed to a space which contains dense edema fluid (D2, ed). In E1, the AE2 cell also contains LB and forms tight junctions (tj) with neighboring cells. The airspace (air) is visible in E1 at the bottom. The AE1 cell is severely injured so that the basal lamina (bl) is denuded (asterisk). cap.: capillary lumen investigate whether such findings could be reproduced in human IPF lungs, tissue from healthy and IPF explants of previous studies was re-analyzed [18, 42]. In healthy human lungs, individual interalveolar septa were detected and AE2 cells had direct contact to alveolar airspaces (Fig. 9a and b). In IPF diseased lungs, however, profiles of AE2 cells were observed quite frequently between thickened and fibrotic alveolar walls (Fig. 9c-e). The identification of these cells was based on the existence of lamellar bodies, microvilli, tight junctions, and a basal lamina. In some cases, these AE2 cells were in contact with edema-filled lacunae (Fig. 9c). Hence, the TGF- $\beta 1$ model seems to reflect alterations of AE2 cells, which can be observed in a similar way in the IPF lung.

\section{Discussion}

Effects of active TGF- $\beta 1$ on AE2 cells include the downregulation of SPs B and C, and other factors involved in surfactant biosynthesis $[11,17]$. During the expression of a porcine-derived active TGF- $\beta 1$, the surface tension lowering capacity of broncho-alveolar lavage-derived surfactant has therefore been shown to be severely impaired. As a result, high surface tension and alveolar collapse dominated the early phase following TGF- $\beta 1$ gene transfer, and predated fibrotic remodeling of lung parenchyma and ultrastructural abnormalities of AE2 cells such as decline in the surface area of the apical membrane [11]. In the presented study, the relevance of the TGF- $\beta 1$-induced surfactant dysfunction for alveolar collapse, fibrotic remodeling, and AE2 cell alterations was investigated using design-based stereology up to the ultrastructural level in combination with lung mechanical evaluation and hydroxyproline measurement. The data illustrate that surfactant replacement therapy during the first week after adenoviral-mediated gene transfer of TGF- $\beta 1$ to mice lungs was effective in stabilizing alveoli and reducing alveolar size heterogeneity on day 7 (Fig. 2f) and day 14 (Fig. 4f) after gene transfer. In addition, the deposition of collagen fibrils (Fig. 5c) and other 
components of the ECM (Fig. 5d) in the interstitium of alveolar septa was markedly prevented at ultrastructural level at day 14 after gene transfer. Regarding the AE2 cells, surfactant replacement therapy increased the total surface area of the apical membrane of AE2 cells in the lung (Fig. 7). Moreover, strong correlations between the degree of alveolar collapse or alveolar size heterogeneity on the one hand and fibrotic remodeling of septal walls could be established (Fig. 8).

To the best of our knowledge, this is the first report demonstrating that preventive surfactant replacement therapy reduces the establishment of interstitial fibrosis of lung parenchyma in an animal model of pulmonary fibrosis. Also, the presented study demonstrates for the first time a linkage between the degree of alveolar collapse and the degree of collagen deposition in the septal walls. Although the correlations provide no proof of a causal relationship between the impaired alveolar microarchitecture and collagen deposition, it can be concluded that both TGF- $\beta 1$ induced pathologies are dependent on the same factors. Surfactant dysfunction is responsible for alveolar collapse and also involved in collagen deposition. Hence, restoring the surfactant function at the very beginning had positive effects on alveolar microarchitecture and interstitial remodeling.

The central role of intra-alveolar surfactant is to reduce the interfacial surface tension in the alveoli at low lung volumes, e.g., at the end of expiration, so that the alveolar surface area for gas exchange remains roughly constant throughout the respiratory cycle [48]. In addition, by minimizing and at the same time harmonizing interfacial surface tension of alveoli of different sizes [49], surfactant is important to prevent intra-pulmonary pressure gradients, which would result in abnormal alveolar dynamics [50]. These include the phenomenon of "pendelluft", meaning that during the end-expiratory equilibrium and zero flow at the airway opening there is nevertheless flow within in the lung between different alveoli [51]. These two important aspects of surfactant function are also reflected in the stereological data. In the saline-treated TGF- $\beta 1$-challenged lungs, there is a decline in the number of open alveoli and an increase in the volume-weighted mean alveolar volume attributable to alveolar size heterogeneity (Fig. 4f, i). The fact that surfactant replacement therapy was able to attenuate alveolar collapse and alveolar size heterogeneity therefore provides strong structural evidence that the treatment was successful. This conclusion is supported by the increase in the volume of tubular myelin, an active subtype of the intraalveolar surfactant pool, observed after surfactant replacement therapy. An increase in the amount of tubular myelin has also been shown to be linked to an improvement of functional parameters in an animal model of ischemia/ reperfusion injury before [52]. Among structural parameters, the number of open alveoli per lung had the strongest correlation to lung mechanical parameters during the early phase of the model. Hence, it can be concluded that initially high surface tension and its effects on lung structure are decisive for lung mechanical impairments. These observations are in line with previous studies demonstrating a strong link between the numbers of open alveoli and lung mechanical properties in animal models of lung injury and fibrosis [18, 20,27].

During the respiratory cycle, the lung is continuously subjected to deformation both at macro- and micromechanical level. The driving force for volume changes and therefore deformation of the lung results from the transpulmonary pressure gradient, which is the difference between the pleural pressure and the pressure at the airway opening, and this is independent of whether the lung is spontaneously breathing or mechanically ventilated [53]. The transpulmonary pressure gradient includes the elastic recoil pressure, which is the pressure drop along the tissue, or, in other words, the gradient between the pleural pressure and the alveolar pressure $[54,55]$. The elastic recoil pressure strongly depends on the interfacial surface tension in the alveoli and tissue factors. Tissue factors include above all an economically designed network of axial and septal wall fibers of collagen and elastin, which in the mouse lung contribute less than $1 \%$ to the volume of the septal walls [56]. Evidence exists that there is little stretch of septal walls in a healthy lung during the physiological range of breathing involving lung volumes approximately between $40 \%$ and $80 \%$ of total lung capacity [50]. The normal or quiet breathing-related strain at the alveolar level has been estimated as $4 \%$ in linear dimension [57]. In the presence of high surface tension, alveolar collapse, and heterogeneous ventilation of the lung, however, some areas of the lung are excessively stretched and therefore prone to injury and profibrotic remodeling [20]. In their spring model of alveolar interdependence, Mead et al. [54] illustrated that in a network of interdependent airspaces, heterogeneities in mechanical properties can have detrimental effects on lung parenchyma. Non-ventilated airspaces, e.g., due to high surface tension, function as stress concentrators and impose tethering forces on the walls of surrounding, ventilated airspaces. These forces have been estimated to reach dimensions of up to 16 times the average stress concentration [58]. This implicates that even in the range of normal tidal volumes at the organ scale, the existence of local mechanical stress, resulting in locally pronounced deformation of alveoli, is very likely to occur in the presence of microatelectases [20, 54, 58]. Lung injury and activation of endoplasmic reticulum (ER) stress followed by apoptosis of alveolar epithelial cells have been observed as a consequence of increased cellular strain, which corresponded to tidal volumes cyclically passing $80 \%$ of total 
lung capacity [59]. In this context, ER stress and apoptosis are features also observed in lung epithelial cells of IPF patients [60]. Based on the reasoning mentioned above, it might therefore be possible that there is a causal link between high surface tension, alveolar collapse, and mechanical stress, and at the end increased deposition of collagen fibrils within the alveolar septa. The established correlations between parameters of alveolar microarchitecture (e.g., alveolar number and size) and the deposition of ECM in the septal walls are in line with this concept (Fig. 8).

In the context of ventilation-induced lung injury and fibrosis, the causal relevance of alveolar collapse, volutrauma, and mechanical stress for disease progression including the generation of a pro-fibrotic milieu are well accepted [61-63]. Alveolar collapse due to high surface tension leads to redistribution of air within the lung and heterogeneous ventilation inducing volutrauma. Hence, mechanical ventilation of a pre-injured lung can augment the deposition of collagen [62, 64]. In addition, the forces acting on lung parenchyma generated during spontaneous breathing can potentially be harmful. Fine lung parenchyma must withstand the elastic recoil pressure, which is the pressure gradient between the alveolar airspace and the pleural space [53]. Increased effort during spontaneous breathing can result in higher pressure gradients along fine lung parenchyma due to higher negative pressures within the pleural space [65, 66], so that in principle spontaneous breathing can also aggravate lung injury and fibrosis due to abnormally increased deformation of interalveolar septa [67, 68].

Surfactant is a mixture of lipids (mainly phospholipids) and SPs A-D so the observed effects of surfactant replacement therapy might not exclusively be a consequence of decrease in surface tension. The porcine-derived surfactant poractant $a$ used in the present study contains the hydrophobic SP-B and SP-C, which are essential for biophysical properties, e.g., the surface tension reducing characteristics. However, poractant $a$ does not contain SP-A and SP-D, which are primarily part of the innate immune system [69]. Nevertheless, there is emerging evidence that SP-C and bioactive lipids, which are derived or even part of the surfactant system, have effects on immune cells [70]. Hence, unrecognized pharmacological effects of components of poractant $a$, which are independent of the biophysical properties, might also have influenced the outcome observed in the present study. However, the exact mechanism needs further investigation.

On day 7, stereological data demonstrate an increase in collagen and ECM in the group treated with exogenous surfactant, in spite of an increased number of open alveoli. The reason for this observation is unclear but might be due to augmented acute inflammatory response in the lung, which has been reported after surfactant replacement therapy in an ex vivo model [71]. Also, the high viscosity of poractant $a$ could result in an initial deterioration of heterogeneity of ventilation incipiently after airway instillation so that in some regions of the lung stretch of the alveolar septa might initially even increase. Stretch has been shown to be a stimulus for increased ECM deposition in the context of ventilation-induced lung injury. Of note, although between day 7 and day 14 the volume of ECM components in septal walls remained stable in the surfactant-treated group, there was a marked increase of ECM in the salinetreated lungs. It seems that surfactant replacement can acutely augment ECM deposition, but has then beneficial effects on a longer time scale.

In the TGF- $\beta 1$ model, severe alterations of AE2 cells have been observed before [11], which were reproduced in the present study in the Saline groups. At ultrastructural level, AE2 cells were found within thickened interalveolar septa in areas of microatelectases, often co-located with focal accumulation of collagen fibrils (Fig. 5a and b). These AE2 cells were characterized by the presence of lamellar bodies and a basal lamina, which in some cases completely surrounded the profile of the AE2 cell, so that is was not apparent whether or not all AE2 cells demonstrated a polarity and had contact to the alveolar airspaces. Threedimensional modeling revealed that AE2 cells were constructed in a polar manner with apical membranes (Fig. 6 and Supplementary Materials). However, AE2 cells did not have any contact to the alveolar airspace. Instead, they had contact to slender lacunae filled with small amounts of edema, which corresponded to collapsed alveoli. Therefore, the occurrence of AE2 cells within thickened septal walls is rather a direct consequence of alveolar collapse and not an indication of epithelial-to-mesenchymal transition, as the latter would require a loss of polarity and the basal lamina. Due to limitations in spatial resolution, such AE2 cells illustrated in Figs. 5, 6 or 9 could easily be misinterpreted as interstitial cells at light microscopic level, although they are not part of the interstitium. Instead they are part of collapsed alveoli degraded to edema-filled small lacunae, which might later on become subject to collapse induration, a mechanism described in the context of usual and acute interstitial pneumonia $[72,73]$. In the present study, stereological data demonstrated in this regard a reduction of the surface area of the apical membrane of AE2 cells in relation to the basolateral membrane, whereas the volume of intracellular surfactant in AE2 was reduced (Fig. 7). Surfactant replacement therapy could increase both the surface area of the apical membrane of AE2 cells and the intra- and extracellular surfactant pool after TGF- $\beta 1$ gene transfer. At day 14 , a high correlation between the surface area of the apical membrane of AE2 cells and the number of open alveoli, as well as the alveolar size heterogeneity, was established 
(Fig. 8d/ f), illustrating that AE2 cell changes and alterations in the alveolar architecture are linked. During exocytosis of lamellar bodies, the limiting membrane of the lamellar body fuses with the apical membrane of the AE2 cell so that the apical membrane increases its surface area [74]. Alveolar expansion represents an important stimulus for exocytosis of lamellar bodies[75], but this stimulus is abolished when alveoli collapse. Hence, alveolar collapse as such can at least in part explain the loss of the apical membrane surface area of AE2 cells per lung in the TGF- $\beta 1$ model. Based on these findings, it seems reasonable to assume that in the TGF- $\beta 1$ model a significant proportion of AE2 cells is not functional in terms of surfactant metabolism due to a lack of access to the airspace. Surfactant replacement therapy could have the potential to restore this functionality by stabilizing alveolar airspaces.

In previous studies, the existence of alveolar collapse and collapse induration has also been reported in human IPF samples [6, 18, 72]. Furthermore, in the present study profiles of lamellar bodies containing cells were observed surrounded by severely remodeled lung parenchyma in IPF (Fig. 9). Hence, the observation of AE2 cells or lamellar bodies containing cells "buried" within tissue and without contact to the airspace is a feature that the TGF- $\beta 1$ model shares with human IPF samples. In both cases, this abnormal location of AE2 cells is a consequence of alveolar instability, remodeling, and at the end collapse induration. At the ultrastructural level, Myers and Katzenstein [72, 73] were the first to describe the features of collapse induration in usual interstitial pneumonia and acute interstitial pneumonia, and as pure fibroproliferation could not entirely explain the degradation of lung function they introduced alveolar collapse as an additional factor. Quantitative morphological evaluations of IPF lungs described a dramatic decline in the surface area of alveolar epithelium as a key feature of IPF, whereas there was astonishingly no increase in the volume of tissue in the lung, which the authors also discussed in the context of alveolar collapse [76]. Recent imaging studies provided further evidence that instability of distal airspaces is present in non-remodeled lung parenchyma and might precede the development of pulmonary fibrosis in IPF, so that authors discussed the role of alveolar collapse as a trigger for fibrosis [3]. In line with this suggestion are observations of increased vascular leakage in IPF lungs in areas that are not yet remodeled, indicating that the disease shows activity outside the fibrotic areas detectable by HRCT [26].

The presented study has several limitations. As a control for the surfactant replacement therapy group, a salinetreated group was included. Saline instillation into the lung simulated the same volume challenge, although the viscous property of saline was much different from that of the surfactant. However, as poractant $a$ is dissolved in $\mathrm{NaCl}$ solution, it seemed reasonable to use saline as a control despite differences in viscosity. In addition, repetitive orotracheal intubation and instillation of saline might have aggravated the pathology induced by TGF- $\beta 1$ overexpression. However, a comparison of the structural data of the saline-treated TGF- $\beta 1$ mice from the present study and our previous study where no saline was instilled after TGF$\beta 1$ gene transfer does not provide any evidence that intratracheal saline instillation had an effect on our primary readout parameters [11]. In line with this observation is the fact that repetitive intubations to perform broncho-alveolar lavages did not result in a worsening of the pulmonary elastance in guinea pigs [77]. Compared with previous studies [16], the phenotype of the model was quite mild in the present study, which became in particular apparent considering the discrete (but still significant) increase in the hydroxyproline level (Fig. 5e). Nevertheless, the animals were clinically sick so that although performed by experienced experimenters, some animals died during the therapeutic intervention. Therefore, the dosage of the AdTGF$\beta 1$ was not increased in the present study. Moreover, based on the hypotheses, very early time points including the transition phase from pure microatelectasis (= lung injury) stage to fibrosis were studied. Thus, the therapeutic intervention was used as a preventive strategy during a phase at which surfactant dysfunction was present to evaluate its role in the pathogenesis of fibrosis. However, this study design does not "model" the human patient suffering from established fibrosis [78]. From these observations, it remains unclear whether surfactant replacement therapy is efficient in treating a lung with already established fibrosis as is usually the case at the time point IPF is diagnosed in a patient. Previous analyses of the surfactant system showed that surfactant function recovered as soon as the TGF- $\beta 1$ overexpression declined in this animal model [11]. Therefore, it appears unlikely that surfactant replacement therapy, at least by its biophysical properties, is effective in the advanced stage of the TGF- $\beta 1$ model at which fibrosis is already established. Hence, the efficiency of surfactant replacement therapy via its biophysical properties is likely to be limited to the transition phase from injury to fibrosis. Nevertheless, in view of the fact that in human IPF the pathology demonstrates a temporal heterogeneity, the transition from initiation of the disease toward fibrosis also has a role in clinically progressed stages with progressed symptoms and lung functional impairments. This is supported by recent imaging studies, suggesting that the disease is active in lung regions not yet remodeled [3, 22, 26]. Hence, preventive treatment strategies seem to be not only of relevance for clinically very early or not yet manifest stages of this disease.

In summary, this study for the first time demonstrates that a surfactant replacement therapy induces an alveolar 
stabilization and reduced interstitial ECM deposition in an animal model of pulmonary fibrosis. Preventive reduction of surface tension was efficient in stabilizing alveoli as well as reducing alveolar size heterogeneity, which is potentially combined with reduced local mechanical stress and strain within the lung. An inverse correlation between the number of open alveoli and the degree of deposition of ECM in alveolar septa could be established, illustrating a clear link between these two pathologies. Although providing no definitive proof, these observations support the hypothesis that instability of distal airspaces, as observed in IPF lungs, might represent a potential trigger for a pro-fibrotic remodeling.

Acknowledgements We thank Susanne Fassbender, Karin Westermann, Sabine Fiedler, Regina Maus, and Jennifer Stolper for excellent technical assistance. We also thank Sheila Fryk for proofreading of the manuscript very thoroughly. This work was supported by a grant of the German Research Foundation (DFG) to LK (KN 916/1-1) and the Federal Ministry for Science and Education (BMBF) via the German Center for Lung Research (DZL).

\section{Compliance with ethical standards}

Conflict of interest The authors declare that they have no conflict of interest.

Publisher's note: Springer Nature remains neutral with regard to jurisdictional claims in published maps and institutional affiliations.

\section{References}

1. Ley B, Ryerson CJ, Vittinghoff E, et al. A multidimensional index and staging system for idiopathic pulmonary fibrosis. Ann Intern Med. 2012;156:684-91.

2. Raghu G, Collard HR, Egan JJ, et al. An official ATS/ERS/JRS/ ALAT statement: idiopathic pulmonary fibrosis: evidence-based guidelines for diagnosis and management. Am J Respir Crit Care Med. 2011;183:788-824.

3. Mai C, Verleden SE, McDonough JE, et al. Thin-section CT features of idiopathic pulmonary fibrosiscorrelated with micro-CT and histologic analysis. Radiology. 2017;283:252-63.

4. American Thoracic Society/EuropeanRespiratory Society International Multidisciplinary Consensus Classification of the Idiopathic Interstitial Pneumonias. This joint statement of the American Thoracic Society (ATS), and the European Respiratory Society (ERS) was adopted by the ATS board of directors, June 2001 and by the ERS Executive Committee, June 2001. Am J Respir Crit Care Med. 2002;165:277-304.

5. Katzenstein A, Mukhopadhyay S, Myers J. Diagnosis of usual interstitial pneumonia and distinction from other fibrosing interstitial lung diseases. Hum Pathol. 2008;39:1275-94.

6. Knudsen L, Ruppert C, Ochs M. Tissue remodelling in pulmonary fibrosis. Cell Tissue Res. 2017;367:607-26.

7. Prud'homme GJ. Pathobiology of transforming growth factor beta in cancer, fibrosis and immunologic disease, and therapeutic considerations. Lab Invest. 2007;87:1077-91.

8. Sime PJ, Xing Z, Graham FL, et al. Adenovector-mediated gene transfer of active transforming growth factor-betal induces prolonged severe fibrosis in rat lung. J Clin Invest. 1997;100:768-76.
9. Rodt T, von Falck C, Dettmer S, et al. Micro-computed tomography of pulmonary fibrosis in mice induced by adenoviral gene transfer of biologically active transforming growth factor- $\beta 1$. Respir Res. 2010;11:181.

10. Ask K, Labiris R, Farkas L, et al. Comparison between conventional and "clinical" assessment of experimental lung fibrosis. J Transl Med. 2008;6:16.

11. Lopez-Rodriguez E, Boden C, Echaide M, et al. Surfactant dysfunction during overexpression of TGF- $\beta 1$ precedes profibrotic lung remodeling in vivo. Am J Physiol Lung Cell Mol Physiol. 2016;310:L1260-1271.

12. Zhao J, Shi W, Wang YL, et al. Smad3 deficiency attenuates bleomycin-induced pulmonary fibrosis in mice. Am J Physiol Lung Cell Mol Physiol. 2002;282:L585-593.

13. Bonniaud P, Kolb M, Galt T, et al. Smad3 null mice develop airspace enlargement and are resistant to TGF-beta-mediated pulmonary fibrosis. J Immunol. 2004;173:2099-108.

14. Hinz B, Suki B. Does breathing amplify fibrosis? Am J Respir Crit Care Med. 2016;194:9-11.

15. Froese AR, Shimbori C, Bellaye PS, et al. Stretch-induced activation of transforming growth factor- $\beta 1$ in pulmonary fibrosis. Am J Respir Crit Care Med. 2016;194:84-96.

16. Knippenberg S, Ueberberg B, Maus R, et al. Streptococcus pneumoniae triggers progression of pulmonary fibrosis through pneumolysin. Thorax. 2015;70:636-46.

17. Correll KA, Edeen KE, Zemans RL, et al. TGF beta inhibits expression of SP-A, SP-B, SP-C, but not SP-D in human alveolar type II cells. Biochem Biophys Res Commun. 2018; 499:843-8.

18. Lutz D, Gazdhar A, Lopez-Rodriguez E, et al. Alveolar derecruitment and collapse induration as crucial mechanisms in lung injury and fibrosis. Am J Respir Cell Mol Biol. 2015;52:232-43.

19. Birkelbach B, Lutz D, Ruppert C, et al. Linking progression of fibrotic lung remodeling and ultrastructural alterations of alveolar epithelial type II cells in the amiodarone mouse model. Am J Physiol Lung Cell Mol Physiol. 2015;309:L63-L75.

20. Knudsen L, Lopez-Rodriguez E, Berndt L, et al. Alveolar micromechanics in bleomycin-induced lung injury. Am J Respir Cell Mol Biol. 2018 https://doi.org/10.1165/rcmb.2018-0044OC).

21. Leslie KO. Idiopathic pulmonary fibrosis may be a disease of recurrent, tractional injury to the periphery of the aging lung: a unifying hypothesis regarding etiology and pathogenesis. Arch Pathol Lab Med. 2012;136:591-600.

22. Petroulia V, Funke M, Zumstein P, et al. Increased expiratory computed tomography density reveals possible abnormalities in radiologically preserved lung parenchyma in idiopathic pulmonary fibrosis. Invest Radiol. 2018;53:45-51.

23. Cottin V, Cordier JF. Velcro crackles: the key for early diagnosis of idiopathic pulmonary fibrosis? Eur Respir J. 2012;40:519-21.

24. Vyshedskiy A, Alhashem RM, Paciej R, et al. Mechanism of inspiratory and expiratory crackles. Chest. 2009;135:156-64.

25. Günther A, Schmidt R, Nix F, et al. Surfactant abnormalities in idiopathic pulmonary fibrosis, hypersensitivity pneumonitis and sarcoidosis. Eur Respir J. 1999;14:565-73.

26. Montesi SB, Rao R, Liang LL, et al. Gadofosveset-enhanced lung magnetic resonance imaging to detect ongoing vascular leak in pulmonary fibrosis. Eur Respir J. 2018;51: pii: 1800171.

27. Steffen L, Ruppert C, Hoymann HG, et al. Surfactant replacement therapy reduces acute lung injury and collapse induration-related lung remodeling in the bleomycin model. Am J Physiol Lung Cell Mol Physiol. 2017;313:L313-L327.

28. Matute-Bello G, Downey G, Moore BB, et al. An official American Thoracic Society workshop report: features and measurements of experimental acute lung injury in animals. Am J Respir Cell Mol Biol. 2011;44:725-38. 
29. Hantos Z, Daróczy B, Suki B, et al. Input impedance and peripheral inhomogeneity of dog lungs. $J$ Appl Physiol. 1992;72:168-78.

30. Salazar E, Knowles JH. An analysis of pressure-volume characteristics of the lungs. J Appl Physiol. 1964;19:97-104.

31. Scherle W. A simple method for volumetry of organs in quantitative stereology. Mikroskopie. 1970;26:57-60.

32. Tschanz S, Schneider JP, Knudsen L. Design-based stereology: planning, volumetry and sampling are crucial steps for a successful study. Ann Anat. 2014;196:3-11.

33. Schneider JP, Ochs M. Alterations of mouse lung tissue dimensions during processing for morphometry: a comparison of methods. Am J Physiol Lung Cell Mol Physiol. 2014;306: L341-350.

34. Muhlfeld C, Knudsen L, Ochs M. Stereology and morphometry of lung tissue. Meth Mol Biol (Clifton, NJ). 2013;931:367-90.

35. Gundersen H. The smooth fractionator. J Microsc. 2002;207(Pt 3):191-210.

36. Woessner JF. The determination of hydroxyproline in tissue and protein samples containing small proportions of this imino acid. Arch Biochem Biophys. 1961;93:440-7.

37. Weibel ER, Hsia CC, Ochs M. How much is there really? Why stereology is essential in lung morphometry. J Appl Physiol. 2007;102:459-67.

38. Hsia CC, Hyde DM, Ochs M, et al. An official research policy statement of the American Thoracic Society/European Respiratory Society: standards for quantitative assessment of lung structure. Am J Respir Crit Care Med. 2010;181:394-418.

39. Mühlfeld C, Ochs M. Quantitative microscopy of the lung: a problem-based approach. Part 2: stereological parameters and study designs in various diseases of the respiratory tract. Am J Physiol Lung Cell Mol Physiol. 2013;305:L205-221.

40. Ochs M. A brief update on lung stereology. J Microsc. 2006;222 (Pt 3):188-200.

41. Mathieu O, Cruz-Orive L, Hoppeler H, et al. Measuring error and sampling variation in stereology: comparison of the efficiency of various methods for planar image analysis. J Microsc. 1981;121 (Pt 1):75-88.

42. Ochs M, Nyengaard LR, Jung A, et al. The number of alveoli in the human lung. Am J Respir Crit Care Med. 2004;169:120-4.

43. Fehrenbach A, Ochs M, Wittwer T, et al. Stereological estimation of the volume weighted mean volumes of alveoli and acinar pathways in the rat lung to characterise alterations after ischaemia/ reperfusion. J Anat. 1999;194(Pt 1):127-35.

44. Gundersen H, Bagger P, Bendtsen T, et al. The new stereological tools: disector, fractionator, nucleator and point sampled intercepts and their use in pathological research and diagnosis. APMIS. 1988;96:857-81.

45. Tschanz SA, Burri PH, Weibel ER. A simple tool for stereological assessment of digital images: the STEPanizer. J Microsc. 2011;243:47-59.

46. Deerinck TJB Lev-Ram, EA V, Shu XT, et al. Enhancing serial block-face scanning electronmicroscopy to enable high resolution 3-D nanohistology of cells and tissues. Microsc Microanal. 2010;16:1138-9.

47. Ochs M. The closer we look the more we see? Quantitative microscopic analysis of the pulmonary surfactant system. Cell Physiol Biochem. 2010;25:27-40.

48. Bachofen $\mathrm{H}$, Schürch S, Urbinelli $\mathrm{M}$, et al. Relations among alveolar surface tension, surface area, volume, and recoil pressure. J Appl Physiol. 1987;62:1878-87.

49. Schürch S. Surface tension at low lung volumes: dependence on time and alveolar size. Respir Physiol. 1982;48:339-55.

50. Knudsen L, Ochs M. The micromechanics of lung alveoli: structure and function of surfactant and tissue components. Histochem Cell Biol. 2018 https://doi.org/10.1007/s00418-018-1747-9).
51. Tabuchi A, Nickles HT, Kim M, et al. Acute lung injury causes asynchronous alveolar ventilation that can be corrected by individual sighs. Am J Respir Crit Care Med. 2016; 193:396-406.

52. Muhlfeld C, Becker L, Bussinger C, et al. Exogenous surfactant in ischemia/reperfusion: effects on endogenous surfactant pools. $\mathrm{J}$ Heart Lung Transplant. 2010;29:327-34.

53. Loring SH, Topulos GP, Hubmayr RD. Transpulmonary pressure: the importance of precise definitions and limiting assumptions. Am J Respir Crit Care Med. 2016;194:1452-7.

54. Mead J, Takishima T, Leith D. Stress distribution in lungs: a model of pulmonary elasticity. J Appl Physiol. 1970; 28:596-608.

55. Fredberg JJ, Kamm RD. Stress transmission in the lung: pathways from organ to molecule. Annu Rev Physiol. 2006;68:507-41.

56. Bachofen H, Schürch S. Alveolar surface forces and lung architecture. Comp Biochem Physiol A Mol Integr Physiol. 2001;129:183-93.

57. Roan E, Waters CM. What do we know about mechanical strain in lung alveoli? Am J Physiol Lung Cell Mol Physiol. 2011;301: L625-635.

58. Makiyama AM, Gibson LJ, Harris RS, et al. Stress concentration around an atelectatic region: a finite element model. Respir Physiol Neurobiol. 2014;201:101-10.

59. Dolinay T, Himes BE, Shumyatcher M, et al. Integrated stress response mediates epithelial injury in mechanical ventilation. Am J Respir Cell Mol Biol. 2017;57:193-203.

60. Korfei M, Ruppert C, Mahavadi P, et al. Epithelial endoplasmic reticulum stress and apoptosis in sporadic idiopathic pulmonary fibrosis. Am J Respir Crit Care Med. 2008;178:838-46.

61. Slutsky AS, Ranieri VM. Ventilator-induced lung injury. N Engl J Med. 2013;369:2126-36.

62. Cabrera-Benítez NE, Parotto M, Post M, et al. Mechanical stress induces lung fibrosis by epithelial-mesenchymal transition. Crit Care Med. 2012;40:510-7.

63. Zhang R, Pan Y, Fanelli V, et al. Mechanical stress and the induction of lung fibrosis via the midkine signaling pathway. Am J Respir Crit Care Med. 2015;192:315-23.

64. Heise RL, Stober V, Cheluvaraju C, et al. Mechanical stretch induces epithelial-mesenchymal transition in alveolar epithelia via hyaluronan activation of innate immunity. J Biol Chem. 2011;286:17435-44.

65. Yoshida T, Uchiyama A, Matsuura N, et al. Spontaneous breathing during lung-protective ventilation in an experimental acute lung injury model: high transpulmonary pressure associated with strong spontaneous breathing effort may worsen lung injury. Crit Care Med. 2012;40:1578-85.

66. Bellani G, Grasselli G, Teggia-Droghi M, et al. Do spontaneous and mechanical breathing have similar effects on average transpulmonary and alveolar pressure? A clinical crossover study. Crit Care. 2016;20:142.

67. Mascheroni D, Kolobow T, Fumagalli R, et al. Acute respiratory failure following pharmacologically induced hyperventilation: an experimental animal study. Intensive Care Med. 1988;15:8-14.

68. Ikegami M, Whitsett JA, Martis PC, et al. Reversibility of lung inflammation caused by SP-B deficiency. Am J Physiol Lung Cell Mol Physiol. 2005;289:L962-970.

69. Wright J. Immunoregulatory functions of surfactant proteins. Nat Rev Immunol. 2005;5:58-68.

70. Fessler MB, Summer RS. Surfactant lipids at the hostenvironment interface. Metabolic sensors, suppressors, and effectors of inflammatory lung disease. Am J Respir Cell Mol Biol. 2016;54:624-35.

71. Stamme C, Brasch F, von Bethmann A, et al. Effect of surfactant on ventilation-induced mediator release in isolated perfused mouse lungs. Pulm Pharmacol Ther. 2002;15:455-61. 
72. Myers J, Katzenstein A. Epithelial necrosis and alveolar collapse in the pathogenesis of usual interstitial pneumonia. Chest. 1988;94:1309-11.

73. Katzenstein A. Pathogenesis of "fibrosis" in interstitial pneumonia: an electron microscopic study. Hum Pathol. 1985; 16:1015-24.

74. Knudsen L, Waizy H, Fehrenbach H, et al. Ultrastructural changes of the intracellular surfactant pool in a rat model of lung transplantation-related events. Respir Res. 2011;12:10.

75. Dietl P, Liss B, Felder E, et al. Lamellar body exocytosis by cell stretch or purinergic stimulation: possible physiological roles, messengers and mechanisms. Cell Physiol Biochem. 2010;25:1-12.

76. Coxson HO, Hogg JC, Mayo JR, et al. Quantification of idiopathic pulmonary fibrosis using computed tomography and histology. Am J Respir Crit Care Med. 1997;155:1649-56.

77. Pliss LB, Ingenito EP, Ingram RH. Baseline lung function and inflammatory indices in guinea pigs: effects of growth, repeated lavage, and orotracheal intubation. Exp Lung Res. 1990;16:617-26.

78. Bonniaud P, Fabre A, Frossard N, et al. Optimising experimental research in respiratory diseases: an ERS statement. Eur Respir J. 2018;51:pii: 1702133 . 